\title{
Involvement and Targeted Intervention of Mortalin- Regulated Proteome Phosphorylated-Modification in Hepatocellular Carcinoma
}

\author{
Ye Yang \\ Nanjing Medical University \\ Ming Jin \\ Nanjing Medical University \\ Yi Dai \\ Nanjing Medical University \\ Wenqi Shan \\ Nanjing Medical University \\ Shuai Chen \\ Nanjing Medical University \\ Rong Cai \\ Nanjing Medical University \\ Haojun Yang \\ Nanjing Medical University \\ Liming Tang ( $\square$ liming_tang@sina.cn ) \\ Nanjing Medical University \\ Lei Li \\ Nanjing Medical University
}

\section{Research}

Keywords: hepatocellular carcinoma, angiogenesis and sorafenib resistance, mortalin, proteome phosphorylated-modification, targeted intervention

Posted Date: October 8th, 2020

DOl: https://doi.org/10.21203/rs.3.rs-86071/v1

License: (c) (i) This work is licensed under a Creative Commons Attribution 4.0 International License.

Read Full License 
Version of Record: A version of this preprint was published at Frontiers in Oncology on July 29th, 2021. See the published version at https://doi.org/10.3389/fonc.2021.687871. 


\section{Abstract}

\section{Background}

Angiogenesis and sorafenib resistance are the main obstacles to the treatment of advanced/recurrent hepatocellular carcinoma (HCC).

\section{Methods}

Three HCC cell lines, HepG2 and Hep3B, and sorafenib-resistant HuH7, and xenografts in nude mice were used as experimental models. A cohort of $126 \mathrm{HCC}$ patients and a cohort of 34 advanced recurrent HCC patients receiving sorafenib therapy were used to indicate the clinical significance.

Results

Mortalin regulated the phosphorylated-modification of cancer associated proteome, causing the angiogenesis and sorafenib resistance in HCC cells. For one of the molecular mechanisms, via regulating the PI-3K/Akt, mortalin activated the VEGF/VEGFR2 and $\beta$-Catenin/Bcl-XL/anti-apoptosis signaling. Treatment the sorafenib resistant xenografts with sorafenib combining with mortalin knockdown facilitated the sorafenib-inhibited tumor growth and angiogenesis, and enhanced the apoptosis. Mortalin was a potential risk factor of HCC, predicting poor prognosis and sorafenib resistance. We finally revealed that, caffeic acid $\left(\mathrm{CaA}, \mathrm{C}_{9} \mathrm{H}_{8} \mathrm{O}_{4}\right)$ could bind to and induce the ubiquitination degradation of mortalin, leading to the inhibition of PI-3K/Akt, VEGF/VEGFR2, and $\beta$-Catenin/Bcl-XL/anti-apoptosis signal pathways.

Conclusions

Mortalin, which regulated the phosphorylated-modification of cancer associated proteome, caused angiogenesis and sorafenib resistance, and was a competitive risk factor of HCC. CaA could be recognized as a novel chemical inhibitor, targeting mortalin in HCC.

\section{Background}

Hepatocellular carcinoma (HCC) is one of the most common solid tumors, and the fourth leading cause of cancer-related mortality worldwide [1]. Up to date, the long-term outcome of HCC is poor because of the high recurrence/metastasis ratio [2]. The hematogenous metastasis represents a major shift in HCC biology; in fact, the tumor angiogenesis, which plays a critical role in providing oxygen and nutrients, is necessary for HCC growth, intra-hepatic and extra-hepatic metastasis and post-surgical recurrence [3]. So in addition to the curative therapies, resection or transplantation (for treatment of early-stage HCC, minority), the strategies of anti-angiogenesis, such as sorafenib, have become the main approaches for treatment of advanced and recurrent HCC (majority) [4]. However, the therapeutic effects of these antiangiogenesis treatments are less than satisfactory. This is largely due to the angiogenesis and sorafenib 
resistance [5,6]. Consequently, the continued search for novel therapeutic strategies for HCC is urgently needed.

Mortalin is the stress-inducible molecular chaperones that belong to the heat shock protein family [7]. Overexpression of mortalin is associated with the increased malignancy, angiogenesis, metastasis, and early recurrence in $\mathrm{HCC}[8,9]$. For the possible mechanisms, mortalin classically sequestrates the p53 in the cytoplasm, leading the inactivation of p53 function and suppressing the apoptosis [10]. However, unlike HCC in the Western countries (display a low frequency of p53 mutations ranging between $10 \%$ to $20 \%$ ), the HCC samples from the Southeast Asia (e.g. China and Japan) harbor high frequency of p53 mutations (up to $60 \%$ ) owing to chronic hepatitis B infection and aflatoxin B1 exposure [11, 12]. Furthermore, increased expression of mortalin was mainly closely associated with cell protection, which could promote the survival of cells under lethal conditions and played a "guardian" role to combat stress and apoptosis [13]. Collectively, in addition to the classical repression of p53 activity, the molecular mechanisms underlying in the cancer-promoting functions induced by mortalin in $\mathrm{HCC}$ are very complicated.

In our present study, we focused on revealing a p53-independent mechanism of mortalin which leading to angiogenesis and sorafenib resistance of $\mathrm{HCC}$ both in vitro and in vivo. Furthermore, we also continued to identify the novel potential chemical inhibitors of mortalin via computer docking and molecular biology verification.

\section{Methods}

\section{Cell culture and Reagents}

The HCC cell lines, HepG2 (wild type p53) and Hep3B (p53 null) were obtained from Institute of Biochemistry and Cell Biology, Shanghai Institutes for Biological Sciences, Chinese Academy of Sciences. The high angiogenic ability and sorafenib-resistance $\mathrm{HuH7}$ cell line (HuH7 ${ }^{\mathrm{SR}}$, mutant p53) was established as described previously [14]. Cells were cultured in Dulbecco's Modified Eagle Medium (DMEM, Life Technologies/Gibco, Grand Island, NY), supplemented with 10\% fetal bovine serum, 100 $\mathrm{U} / \mathrm{ml}$ penicillin, and $100 \mu \mathrm{g} / \mathrm{ml}$ streptomycin (Gibco), in a $37^{\circ} \mathrm{C}$ humidified incubator with $5 \% \mathrm{CO}_{2}$. A mycoplasma stain assay Kit (Beyotime Co. Ltd, Haimen, China) was used for mycoplasma testing. Sorafenib (>99.89\% purity) was purchased from Selleckchem Co. Ltd (Houston,TX, USA), while 3,4dihydroxycinnamic acid (caffeic acid, $\mathrm{CaA}, \mathrm{C}_{9} \mathrm{H}_{8} \mathrm{O}_{4}, \geq 98.0 \%$ purity) and MKT-077 (mortalin inhibitor, $\geq 98.0 \%$ purity) were purchased from Sigma-Aldrich (Shanghai, China). All other reagents used in the present study were of analytical grade or the highest grade available.

\section{Xenograft in nude mice and immunohistochemistry (IHC)}

The in vivo protocols were approved by the Nanjing Medical University Institutional Animal Care and Use Committee (2017-KY010). BALB/c nude mice were obtained from the SLRC Laboratory Animal Center (Shanghai, China) and conventional kept in a specific pathogen-free and temperature-controlled 
environment $\left(20-22^{\circ} \mathrm{C}\right)$ with a $12 \mathrm{~h}$ light-dark cycle and free access to drinking water and chow as described previously [14]. For the xenograft study, $2 \times 10^{6}$ cells in $100 \mu l$ matrigel were injected subcutaneously into the right armpit of mice for 3 weeks. We used $60 \mathrm{mg} / \mathrm{kg}$.BW of sorafenib (Selleckchem, Houston, TX, USA) via gavage, with scrambled or mortalin-siRNA (Santa Cruz Biotechnology, CA, USA) via intratumoral injection every 3 days as described previously [14]. Tumor volumes were calculated using the formula: $V=1 / 2$ (width ${ }^{2} \times$ length). After 18 days, the mice were killed, and tumor tissues were removed for further investigation. For IHC, sections mounted on silanized slides were dewaxed in xylene; dehydrated in ethanol; boiled in $0.01 \mathrm{M}$ citrate buffer $(\mathrm{pH} \mathrm{6.0)}$ for $20 \mathrm{~min}$ in a microwave oven; and then incubated with $3 \%$ hydrogen peroxide for 5 min. After washing with PBS, sections were incubated in 10\% normal bovine serum albumin for $5 \mathrm{~min}$, followed by incubation with primary antibody at $4^{\circ} \mathrm{C}$ overnight. The slides were then incubated with a horseradish peroxidaseconjugated secondary antibody at room temperature for another $30 \mathrm{~min}$. Samples were then visualized using diaminobenzadine, dehydrated, cleared, mounted, and photographed under a panoramic-scan digital slice scanning system (3DHISTECH Co. Ltd, Budapest, Hungary). The graphs were analyzed using Image-Pro-Plus 6.0 software as described previously $[14,15]$. The criteria of immunostaining score was listed in additional files, Table. S1.

\section{Patients and tissue microarray}

This study was approved by Medical Ethics Committee of the Affiliated Changzhou No. 2 Hospital of Nanjing Medical University, and the participants' written informed consents were obtained from each patient for the study of tissue excised from surgical specimens. The clinic-pathologic data was listed in additional files, Tables. S2 and S3. The tissue microarray was constructed by Shanghai Zhuoli Biotechnology Co. Ltd (Zhuoli Biotechnology Co, Shanghai, China). In each case, 1-2 $\mu \mathrm{m}$ thick sections from paraffin tissue blocks were cut, dewaxed, pre-treated and diverted to glass slides used with an adhesive tape transfer system in order to ultraviolet cross linkage. All reactions were carried out on an automated staining device (Roche, Ventana Medical Systems, Arizona, USA). The quantitation of immunostaining was performed by two independent researchers who were blinded regarding patient details as describe above.

\section{Phospho-specific protein microarray analysis}

Phosphoprotein profiling were designed and manufactured by using phospho explorer antibody array (PEX100) from Wayen Biotechnology (Shanghai, China). The microarray contains 1318 antibodies, each phosphorylation site were detected by two different kinds of antibodies to identify the phosphorylated and unphosphorylated status. Each antibody has two replicates and located in two symmetrical blocks. GenePix Pro 6.0 software was used to read the original data, including fluorescence signal, background and so on. A ratio computation was used to measure the extent of protein phosphorylation: phosphorylation ratio $=$ phosphorylated value/un-phosphorylated value .

\section{Biological functional analysis}


A search tool for the retrieval of interacting genes (STRING) database (https://string-db.org) was employed to construct the protein-protein interaction. The database for annotation, visualization and integrated discovery (DAVID, http://david.ncifcrf.gov) was employed to process the gene ontology (GO) and Kyoto Encyclopaedia of Genes and Genomes (KEGG) pathway analysis. The $p<0.05$ was set as the cut-off criterion for significant enrichment.

\section{Determination of the binding status of mortalin with CaA or ubiquitin}

After $\mathrm{HuH}^{\mathrm{SR}}$ cells were pre-treated by 0 or $20 \mu \mathrm{M}$ of MG-132, for $2 \mathrm{~h}$, they were exposed to $20 \mu \mathrm{M}$ of CaA for $6 \mathrm{~h}$. Then, such cells were extracted for $30 \mathrm{~min}$ with immunoprecipitation lysis buffer (Beyotime). After centrifugation of the preparations, $100 \mu \mathrm{g}$ of total proteins were incubated with mortalin antibody at $4^{\circ} \mathrm{C}$ overnight. Then the protein-antibody complexes were incubated with IgG sepharose beads (Beyotime) at $4^{\circ} \mathrm{C}$ for another $12 \mathrm{~h}$. After then, the supernatants were removed (positive control) and the beads were washed for three times (residual supernatants, served as a negative control), boiled to remove the beads, centrifugation, and then dissolved the tested substance in water for high-performance liquid chromatography/mass spectrometry (HPLC/MS) analysis, using the Thermo Fisher Q Exactive Plus LCMS system with the CaA standard as positive control. For the determination of protein ubiquitination, a co-immunoprecipitation assay was performed as described previously [16]. Briefly, $\mathrm{HuH} 7^{\mathrm{SR}}$ cells were treated, extracted, and the immunoprecipitation complex was prepared as described above. Then, such samples were analyzed by Western blot assay with ubiquitin antibody.

\section{Functional assays}

For the details of other functional assays, please see the section "supplementary materials and methods" listed in the supplementary files.

\section{Statistical analysis}

Data sets were compared using Graphpad 8.0 (GraphPad Software, Inc, CA, USA). Data were presented as the means $\pm S D$. The differences were analyzed via using student's $t$ test, one-way analysis of variance followed by Dunnett's t test, or two-way analysis of variance followed by Sidak's multiple comparisons test. Survival curves were estimated using the Kaplan-Meier method, and differences in survival distributions were evaluated by the log-rank test. The $p$ values $<0.05$ were considered statistically significant.

\section{Results}

Mortalin caused angiogenesis and sorafenib resistance in HCC cells. Firstly, we evaluated effects of mortalin on the angiogenic abilities in three human HCC cell lines, HepG2, Hep3B, and HuH7 ${ }^{S R}$. Here, the tube formation ability in mortalin-knockdown cells were significantly reduced compared with MOCK group, while forced expression of mortalin exhibited the opposite phenomenon (Figs. 1A and 1B, and additional files, Fig. S1). Next, we further investigated the effects of mortalin on sorafenib resistance in 
the above-mentioned three HCC cell lines. Similarly, knockdown of mortalin decreased the efficiency of sorafenib, while overexpression of mortalin caused the opposite effects. The $\mathrm{IC}_{50} \mathrm{~s}$ of sorafenib in MOCK, mortalin-knockdown, and mortalin-overexpression groups were HepG2 (7.682 vs. 4.214 vs. 12.33), Hep3B (6.362 vs. 2.927 vs. 12.6), and $\mathrm{HuH7}^{\mathrm{SR}}$ (20.14 vs. 10.29 vs. 26.06) (Fig. 1C). Collectively, these results indicated that mortalin might be an effective factor which could improve the angiogenic abilities and contribute to sorafenib resistance in HCC cells. Moreover, mortalin might cause the above-mentioned effects in p53-dependent and p53-independent manners.

\section{Mortalin regulated phosphorylated modification of cancer associated proteome in HCC cells.}

In addition to the classic role of mortalin-mediated inactivation of p53, it also improves cancer cell survival and enhances tumour progression (especially in drug-resistant tumours) via other ways like the synergistic effects with human telomerase reverse transcriptase and heterogeneous nuclear ribonucleoprotein $\mathrm{K}$ [17]. Here, we firstly employed a search tool for the retrieval of interacting genes (STRING) database to further predict the mortalin-regulated potential downstream signal transduction mechanisms. Mortalin was taken as the central molecule, and then constructed a protein-protein interaction via the generation of 20 most frequently altered neighbor interactors and 30 indirect interactors around it (additional files, Fig. S2). Next, we employed the database for annotation, visualization and integrated discovery (DAVID) to conduct KEGG pathway analysis based on the abovementioned 50 factors. The enrichment results showed 8 pathways related to the functions of mortalin identified and the oxidative phosphorylation was ranked the first (Fig. 2A). So, to further clarify the effects of mortalin on proteomics phosphorylation modification, a phospho-antibody microarray was used in MOCK and mortalin-knockdown HuH7 ${ }^{\text {SR }}$ cells. We identified a protein spectrum with whose phosphorylation levels were more than 1.5 fold changed (50\% increased or $33 \%$ decreased) compared with MOCK group (Fig. 2B). KEGG enrichment analysis of the array indicated that, the PI-3K/Akt pathway was ranked the first (Fig. $2 \mathrm{C}$ and additional files, Fig. S3). Furthermore, many of these phosphorylated proteins are vital to tumor progression, and knockdown of mortalin resulted in the extensive suppression of phosphorylation of proteome. As shown in Fig. 2D, the phosphorylation of VEGFR, IGFR, FGFR and EGFR, the receptors with extracellular signal transduction function declined obviously. The results also revealed a reduction in phosphorylation of many key components crucial for PI-3K/Akt (PI-3K-p85, AKT1), MAPK (MEK1, MKK3/6), NF-KB (IKKß, IKBa, p65, p105/50), JAK-STAT (JAK1/2, STAT1), et al. Meanwhile, several factors involved in the negative regulation exhibited the opposite trend. Collectively, these results indicated that, mortalin could regulate the phosphorylated modification of cancer associated proteome, and that, the $\mathrm{PI}-3 \mathrm{~K} / \mathrm{Akt}$ might be a key downstream pathway regulated by mortalin in high angiogenic activity and sorafenib-resistance HCC cells.

\section{Identification of PI-3K/Akt as an important downstream factor, regulating VEGF and GSK3/ $\beta$-catenin in HCC cells}

Due to the PI-3K/Akt pathway ranked the first in the KEGG enrichment, we further investigated the underlying mechanisms via GO analysis based on proteins enriched in PI-3K/Akt signaling pathway. As 
shown in Fig. 3A, the top biological process was negative regulation of apoptotic. Next, we analyzed the phosphoproteins with the most significant changes in PI-3K/Akt signaling pathway, and listed those downregulated or upregulated at least 2-fold compared with the MOCK group. Here in mortalin-KD cells, the phosphorylation of AKT1, VEGFR2, and Bcl-XL, et al were significantly decreased, while the phosphorylation of p27kiP1 and GSK3 3 , et al were significantly decreased (Fig. 3B). Then, we further investigated the differential phosphorylation protein sites enriched in VEGF/VEGFR, GSK3/ $\beta$-catenin and anti-apoptosis signing, and confirmed that, the above-mentioned three signal pathways were all inactivation in in mortalin-KD cells (Fig. 3C). Based on these results, we speculated that, the PI-3K/Aktregulated VEGF/VEGFR and $\beta$-catenin/anti-apoptosis, were the two mainly neoplastic biological processes involved in mortalin-caused angiogenesis and sorafenib resistance in HCC.

\section{Verification of microarray and bioinformatics results in vitro and in vivo}

Verifying the above-mentioned hypothesis, we firstly determined the functions of mortalin in regulating PI3K/Akt, VEGF/VEGFR, and $\beta$-catenin/anti-apoptosis pathways, as determined by the levels/phosphorylation of PI3K-p85 (Tyr458), Akt (Ser473), VEGFR2 (Tyr951), GSK3 $\beta$ (Tyr216), $\beta$-catenin (Thr41/Ser 45), Bcl-XL, and apoptosis. As shown in Figs. 4A and 4B, knockdown of mortalin decreased the phosphorylation (activation) of PI3K/Akt/VEGFR2; but increased the phosphorylation of GSK3 $\beta$, which in turn inactivated the $\beta$-catenin/Bcl-XL, and enhanced the apoptosis. However, forced expression of mortalin in HepG2 and Hep3B cells showed the opposite effects. Moreover, knockdown of mortalin attenuated the secretion of VEGF (Fig. 4C). Next, we performed in vivo experiments to further confirm our results. As shown in Figs. 4D and $4 \mathrm{E}$, treating the xenografts with sorafenib alone mildly inhibited tumor growth and angiogenesis. However, combining with knockdown of mortalin facilitated the sorafenibcaused inhibition of tumor growth and angiogenesis, and enhanced the apoptosis. Western blot also confirmed the inhibition of PI-3K/Akt, VEGFR, and $\beta$-catenin/anti-apoptosis pathways in mortalin-KD group (Fig. 4F). Collectively, these results suggested that, knockdown of mortalin blocked the PI-3K/Akt, which in-turn inactivated the VEGF/VEGFR and $\beta$-catenin/anti-apoptosis signal pathway, leading to the attenuation of angiogenesis and sorafenib resistance in HCC cells.

\section{The clinical significance of mortalin in HCC}

We then evaluated the expression of mortalin in HCC patients. As shown in Figs. 5A and 5B, compared with adjacent non-tumor liver tissues, a considerable elevation of mortalin was observed in HCC tissues. We then investigated the association between mortalin level and angiogenesis. The HCC specimens were divided into "mortalin-low" vs. "mortalin-high" groups according to the IHC-Q-Scores. The number of microvessels in mortalin-high HCC tissues was significantly more than those in mortalin-low tissues (Fig. 5C). Moreover, a significant positive correlation was found between mortalin levels and number of microvessels (Fig. 5D). We also found that there was a positive correlation between mortalin and 14-3-3n (an angiogenesis and sorafenib resistance inducer, which was confirmed by our previous study [14, 15]) (Fig. 5E). Finally, Kaplan-Meier survival analysis showed that HCC patients in "mortalin-high" group had the worse overall survival and recurrence-free survival than those in "mortalin-low" group (Fig. 5F). The 
survival analysis of 34 advanced recurrent HCC patients (received combined sorafenib treatment and transarterial chemoembolization therapy) exhibited the same trend (Fig. 5G). These results indicated that, mortalin might be regarded as a potential risk factor of HCC, predicting poor prognosis and sorafenib resistance.

\section{Identified a novel potential chemical inhibitor for mortalin: CaA}

MKT-077 $\left(\mathrm{C}_{21} \mathrm{H}_{22} \mathrm{ClN}_{3} \mathrm{OS}_{2}\right)$ is a classic chemical inhibitor of mortalin, functions via abolishing mortalinp53 interactions, but did not change the expression of mortalin [18]. Previous studies revealed that, caffeic acid phenethyl ester (CAPE, $\mathrm{C}_{17} \mathrm{H}_{16} \mathrm{O}_{4}$, a specific inhibitor of $\mathrm{NF}-\mathrm{KB}$ activation) was also able to induce disruption of mortalin-p53 complexes, leading to nuclear translocation and activation of p53, and accompanied with a decrease in the expression of mortalin via transcriptional inactivation [19]. However, the effects of these chemicals on the stability of mortalin protein, remain unclear. Our previous study revealed that, as the same as CAPE, CaA was also an effective NF-KB inhibitor [20], and that NF-KB was an up-stream transcriptional regulator of mortalin [21]. Here, CaA decreased the expression of mortalin mRNA in HepG2, Hep3B, and HuH7 ${ }^{\text {SR }}$ cells (additional files, Fig. S4). Moreover, via a computer docking (SYBYL-X software), we found that the basic skeleton structure of CAPE, $\mathrm{CaA}\left(\mathrm{C}_{9} \mathrm{H}_{8} \mathrm{O}_{4}\right)$ could bind to mortalin, and the binding region of $\mathrm{CaA}$ and mortalin was the same as MKT-077 (Fig. 6A). Thus we adopted a novel approach by combining both IP and LC/MS techniques to reveal the interaction between $\mathrm{CaA}$ and mortalin. The mortalin was immunoprecipitated with its specific antibody and its CaA-binding status was determined by LC/MS to investigate if the immunoprecipitation complex contained $\mathrm{CaA}$. As shown in Fig. 6B, the retention time of $\mathrm{CaA}$ was $3.29 \mathrm{~min}$, and the area of $\mathrm{CaA}$ in positive control group (total protein, supernatant) was $9.6 \times 10^{5}$. The area of $\mathrm{CaA}$ in immunoprecipitated complex (experimental group, sample) was $7.5 \times 10^{5}$. We almost did not detect the presence of $\mathrm{CaA}$ in negative control groups (lysis buffer and residual supernatant). Moreover, $\mathrm{CaA}$ treatment enhanced the ubiquitination of mortalin in $\mathrm{HuH}^{\mathrm{SR}}$ cells (Fig. 6C), decreased the expression/phosphorylation of mortalin, PI3K-p85 (Tyr458), Akt (Ser473), VEGFR2 (Tyr951), $\beta$-catenin (Thr41/Ser 45), and Bcl-XL (Fig. 6D). Finally, we used a previously established MHCC97H cells xenografts model, which was treated by CaA [22, 23], to confirm the effects of $\mathrm{CaA}$ on the expression/phosphorylation of the above-mentioned factors in vivo. As shown in Fig. $6 \mathrm{E}$, $\mathrm{CaA}$ treatment inhibited the mortalin, PI-3K/Akt, VEGFR2, and the $\beta$-catenin/Bcl-XL. Collectively, these results indicated that, $\mathrm{CaA}$ inhibited the mortalin at both transcriptional (indirectly, might via blocking NF$\mathrm{KB}$ ) and post-transcriptional (directly, might via targeting and inducing the ubiquitination and degradation of mortalin) modifications in HCC cells.

\section{Discussion}

Mortalin is a major mitochondrial protein resides in mitochondria, endoplasmic reticulum, the plasma membrane and cytoplasmic vesicles, it participates in various biological processes including proliferation, functional maintenance and stress response in cancer cells, and promotes tumor progression [7, 24]. Studies also revealed that mortalin has an anti-apoptotic function [13]. Loss of 
mortalin induced dysfunction of mitochondria, always accompanied by a decrease in ATP and an increased in ROS generation [25]. There is no contradiction between oxidative phosphorylation and the classic roles of mortalin in regulating ROS generation. Under the environment of redox balance, several key molecules (RAF/RAS, MAPKs, receptors, PI-3K/AKT, JAK/STATs, NF-KB, Wnt/ $\beta$-Catenin, et al) had been abnormal phosphorylated, then led to the ability of anti-apoptosis, epithelial-mesenchymal transition, autophagy, cancer stem cells-like properties and angiogenesis, eventually induced tumor cells to obtain or maintain drug resistance. Meanwhile, the abnormal phosphorylation modification of abovementioned key molecules then regulated a series of key downstream signal molecules, increasing the antioxidant capacity of tumor cells was also one of the essential requirements to obtain/maintain the redox balance. Therefore, in the subset of drug-resistant tumor cells, the disorder of redox balance and the abnormal phosphorylation modification functioned as two parallel biological behaviors, and it is inevitable for them to promote and coexist mutually. While the regulatory role of mortalin in phosphorylation proteomics still remains uninvestigated. Here, we found that, mortalin caused angiogenesis and sorafenib resistance via regulating phosphorylated modification of cancer associated

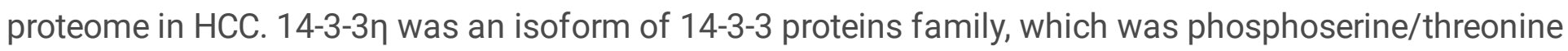
binding proteins of approximate 28 to $33 \mathrm{kDa}$ acidic polypeptides [26]. Our previous studies revealed that, 14-3-3n isoform was a novel characteristic neoplastic factor in HCC, inducing the growth/angiogenesis and MDR properties $[14,15]$. Here, we also found there was a positive correlation between the expressions

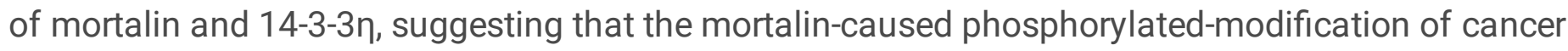
associated proteome might be mediated by $14-3-3 \eta$. This hypothesis needed to be confirmed by further studies.

Mechanically, PI-3K/Akt is a key signaling pathway of particular relevance in cancer progressions, and hyper-phosphorylation of PI-3K and the activated Akt are regarded as crucial factors which contribute to anti-apoptotic, the stability and the normal functions might be disturbed via modulating the phosphorylation [27]. Studies also indicated that signal transduction enhanced by the PI3K/Akt pathway played an important contribute role in neovascularization [28]. Currently, VEGF has been considered the most potential angiogenesis-inducing factor. In the VEGF/VEGFR pathway, VEGFR2 is the most important VEGF receptor. In our study, we found VEGFR2 were down-regulated remarkable including several classic phosphorylate sites like Tyr951 and Tyr1059, which might promote neovascularization and regeneration of tumor cells, contribute to the development of cancer [29, 30]. In addition, GSK3 functions as an important downstream regulatory switch for numerous signaling pathways involved in the formation of tumors, including the regulation of Wnt/ $\beta$-catenin pathway [31,32]. In the pathway, activated AKT could bind to GSK3 $\beta$ complex and then phosphorylate GSK3 $\beta$ at Ser9 and increased the $\beta$-catenin levels [33, 34], while inhibited GSK3 $\beta$ phosphorylation at Tyr216 also caused the activation of $\beta$-catenin [35]. Here, we found the phosphorylation of GSK3 $\beta$ at Ser9 were downregulated while GSK3 $\beta$ at Tyr216 were upregulated in mortalin knockdown cells, which inhibited the phosphorylation of $\beta$-catenin at several main sites such as Ser37, Thr41 and Tyr654. These down-regulation of phosphorylation levels could inhibit $\beta$-catenin separate from cell membrane and prevent it from entering the nucleus to perform function, then promote the cancer progression $[36,37]$. In addition, the downstream apoptosis process 
related gene like $\mathrm{Bcl}-\mathrm{XL}, \mathrm{Bcl}-2$, $\mathrm{BAD}$ were also regulated and leading to the apoptosis process consistent with their functions [38]. From this point of view, mortalin plays an irreplaceable role in the regulation of phosphorylated modification of proteome, leading to the angiogenesis and sorafenib resistance in HCC.

$\mathrm{CaA}$ is a phenolic compound widely synthesized by plants and it is the basic skeleton structure of many phytochemicals including CAPE $[39,40]$. We previously found that, CaA may intervene the progression of $\mathrm{HCC}$ from various aspects. For the inhibition of angiogenesis, $\mathrm{CaA}$ attenuated the activation of HIF-1a via reducing JNK1 activation and reducing HIF-1 a stabilization, also decreased p-STAT-3, leading to an attenuated recruiting of the HIF-1 $a$ and p-STAT-3 to VEGF promoter [22]. Meanwhile, we also found that $\mathrm{CaA}$ attenuated the cancer stem cell-like properties by Epigenetic regulating the TGF $\beta$-SMAD2 signaling pathway [23]. In addition, CaA could block the expression/secretion of endogenous IL- 6 by attenuation of the NF-KB-IL-6-STAT-3 feedback loop in HCC cells [20]. Nevertheless, these above-mentioned effects induced by $\mathrm{CaA}$ were all depend on the indirect ways of signal transduction. Here, our present study revealed that, $\mathrm{CaA}$ played a targeted intervention role on mortalin via inducing the ubiquitination and degradation of mortalin in HCC, suggesting a novel directly manner.

\section{Conclusion}

Our present study revealed that mortalin, which regulated the phosphorylated-modification of cancer associated proteome, caused angiogenesis and sorafenib resistance. Among them, the PI-3K/Aktregulated VEGF/VEGFR2 and $\beta$-Catenin/Bcl-XL/anti-apoptosis signaling play an important role. Moreover, mortalin was a competitive risk factor of HCC, predicting poor prognosis and poor curative effect of sorafenib. Further, we found that $\mathrm{CaA}$ could be recognized as a novel chemical inhibitor, targeting mortalin in HCC (Fig. 7). Our present study not only revealed the partial key process of the mortalininduced $\mathrm{HCC}$ progression, and the anti-cancer functions induced by $\mathrm{CaA}$ and other phytochemicals with similar structure; but also provide a new theoretical basis for further research on the targeted intervention of HCC.

\section{Abbreviations}

AKT, protein kinase B (PKB); Bcl-XL, B-cell leukemia XL; GSK3 $\beta$, glycogen synthase kinase $3 \beta$; $\mathrm{HCC}$, hepatocellular carcinoma; NF-KB, nuclear factor KB; PI-3K, phosphatidylinositol 3-kinase; ROS, reactive oxygen species; VEGFR2, vascular endothelial growth factor receptor 2.

\section{Declarations}

Ethics approval and consent to participate: Not applicable

Consent for publication: Not applicable.

Availability of data and materials: Not applicable. 
Competing interests: The authors have no conflict of interest.

Authors' contributions: LT and LL conceived the research. YY and MJ drafted the manuscript. YY, MJ, and WS performed cell experiments, phospho-specific protein microarray, and biological functional analysis. YD and SC carried out the in vivo xenograft and IHC/TUNEL. RC and HY carried out the patient's sample preparation, follow-up, and statistical analysis of the data. All the authors have read and approved the final version of the manuscript.

\section{Funding}

This work was supported by the National Natural Science Foundation of China (81973096), the Natural Science Foundation of Jiangsu Province (BK20181155), and the Project Funded by Jiangsu Postgraduate Research and Innovation Plan (SJCX19-0316).

\section{Acknowledgements}

Not applicable.

\section{References}

1. Bray, F, et al. Global cancer statistics 2018: GLOBOCAN estimates of incidence and mortality worldwide for 36 cancers in 185 countries. CA Cancer J Clin. 2018. 68(6): 394-424.

2. Forner, A, M Reig, and J Bruix. Hepatocellular carcinoma. Lancet. 2018. 391(10127): 1301-1314.

3. Lin, YL and Y Li. Study on the hepatocellular carcinoma model with metastasis. Genes Dis. 2020. 7(3): 336-350.

4. Dhanasekaran, $\mathrm{R}$, et al. Clinical implications of basic research in hepatocellular carcinoma. $J$ Hepatol. 2016. 64(3): 736-745.

5. Tang, $\mathrm{W}$, et al. The mechanisms of sorafenib resistance in hepatocellular carcinoma: theoretical basis and therapeutic aspects. Signal Transduct Target Ther. 2020. 5(1): 87.

6. Zhu, XD, ZY Tang, and HC Sun. Targeting angiogenesis for liver cancer: Past, present, and future. Genes Dis. 2020. 7(3): 328-335.

7. Lee, AS. Glucose-regulated proteins in cancer: molecular mechanisms and therapeutic potential. Nat Rev Cancer. 2014. 14(4): 263-276.

8. Chen, $\mathrm{J}$, et al. Overexpression of Mortalin in hepatocellular carcinoma and its relationship with angiogenesis and epithelial to mesenchymal transition. Int J Oncol. 2014. 44(1): 247-255.

9. Cho, W, et al. The Molecular Chaperone Heat Shock Protein 70 Controls Liver Cancer Initiation and Progression by Regulating Adaptive DNA Damage and Mitogen-Activated Protein Kinase/Extracellular Signal-Regulated Kinase Signaling Pathways. Mol Cell Biol. 2019. 39(9):

10. Lu, WJ, et al. Induction of mutant p53-dependent apoptosis in human hepatocellular carcinoma by targeting stress protein mortalin. Int J Cancer. 2011. 129(8): 1806-1814. 
11. Nault, JC and J Zucman-Rossi. Genotype-phenotype relationships in hepatocellular carcinoma: p53 inactivation promotes tumors with stem cell features. Gastroenterology. 2012. 142(5): 1066-1069.

12. Woo, HG, et al. Association of TP53 mutations with stem cell-like gene expression and survival of patients with hepatocellular carcinoma. Gastroenterology. 2011. 140(3): 1063-1070.

13. Kaul, SC, CC Deocaris, and R Wadhwa. Three faces of mortalin: a housekeeper, guardian and killer. Exp Gerontol. 2007. 42(4): 263-274.

14. Qiu, Y, et al. Reversal of sorafenib resistance in hepatocellular carcinoma: epigenetically regulated disruption of 14-3-3eta/hypoxia-inducible factor-1alpha. Cell Death Discov. 2019. 5(120.

15. Shen, J, et al. 14-3-3eta is a novel growth-promoting and angiogenic factor in hepatocellular carcinoma. J Hepatol. 2016. 65(5): 953-962.

16. Qiu, Y, et al. Arsenic trioxide reverses the chemoresistance in hepatocellular carcinoma: a targeted intervention of 14-3-3eta/NF-kappaB feedback loop. J Exp Clin Cancer Res. 2018. 37(1): 321.

17. Ryu, J, et al. Identification and functional characterization of nuclear mortalin in human carcinogenesis. J Biol Chem. 2014. 289(36): 24832-24844.

18. Miyata, $\mathrm{Y}$, et al. Synthesis and initial evaluation of YM-08, a blood-brain barrier permeable derivative of the heat shock protein 70 (Hsp70) inhibitor MKT-077, which reduces tau levels. ACS Chem Neurosci. 2013. 4(6): 930-939.

19. Wadhwa, R, et al. Molecular Characterization and Enhancement of Anticancer Activity of Caffeic Acid Phenethyl Ester by gamma Cyclodextrin. J Cancer. 2016. 7(13): 1755-1771.

20. Wang, $L L$, et al. Caffeic acid attenuates the autocrine IL-6 in hepatocellular carcinoma via the epigenetic silencing of the NF-kappa B-IL-6-STAT-3 feedback loop. Rsc Advances. 2015. 5(65): 52952-52957.

21. $\mathrm{Li}, \mathrm{Y}$, et al. mot-2-Mediated cross talk between nuclear factor-B and p53 is involved in arseniteinduced tumorigenesis of human embryo lung fibroblast cells. Environ Health Perspect. 2010. 118(7): 936-942.

22. $\mathrm{Gu}, \mathrm{WT}$, et al. Caffeic acid attenuates the angiogenic function of hepatocellular carcinoma cells via reduction in JNK-1-mediated HIF-1 alpha stabilization in hypoxia. Rsc Advances. 2016. 6(86): 8277482782.

23. $\mathrm{Li}, \mathrm{Y}$, et al. Blockage of TGFbeta-SMAD2 by demethylation-activated miR-148a is involved in caffeic acid-induced inhibition of cancer stem cell-like properties in vitro and in vivo. FEBS Open Bio. 2015. 5(466-475.

24. Srivastava, S, et al. Evolving paradigms on the interplay of mitochondrial Hsp70 chaperone system in cell survival and senescence. Crit Rev Biochem Mol Biol. 2019. 54(6): 517-536.

25. Tai-Nagara, I, et al. Mortalin and DJ-1 coordinately regulate hematopoietic stem cell function through the control of oxidative stress. Blood. 2014. 123(1): 41-50.

26. Cau, Y, et al. Structure, Function, Involvement in Diseases and Targeting of 14-3-3 Proteins: An Update. Curr Med Chem. 2018. 25(1): 5-21. 
27. Yuan, TL and LC Cantley. PI3K pathway alterations in cancer: variations on a theme. Oncogene. 2008. 27(41): 5497-5510.

28. Bader, AG, et al. Oncogenic PI3K deregulates transcription and translation. Nat Rev Cancer. 2005. 5(12): 921-929.

29. Koch, S and L Claesson-Welsh. Signal transduction by vascular endothelial growth factor receptors. Cold Spring Harb Perspect Med. 2012. 2(7): a006502.

30. Negri, FV, et al. Expression of pERK and VEGFR-2 in advanced hepatocellular carcinoma and resistance to sorafenib treatment. Liver Int. 2015. 35(8): 2001-2008.

31. Juhlin, CC, et al. Loss of expression for the Wnt pathway components adenomatous polyposis coli and glycogen synthase kinase 3-beta in parathyroid carcinomas. Int J Oncol. 2009. 34(2): 481-492.

32. Li, R, et al. Cytoplasmic accumulation of glycogen synthase kinase-3beta is associated with aggressive clinicopathological features in human prostate cancer. Anticancer Res. 2009. 29(6): 20772081.

33. Fukumoto, S, et al. Akt participation in the Wnt signaling pathway through Dishevelled. J Biol Chem. 2001. 276(20): 17479-17483.

34. Zheng, $\mathrm{CH}$, et al. CDK5RAP3 suppresses Wnt/beta-catenin signaling by inhibiting AKT phosphorylation in gastric cancer. J Exp Clin Cancer Res. 2018. 37(1): 59.

35. Huang, YF, et al. FIBP knockdown attenuates growth and enhances chemotherapy in colorectal cancer via regulating GSK3beta-related pathways. Oncogenesis. 2018. 7(9): 77.

36. Lin, J, et al. GSK-3beta in DNA repair, apoptosis, and resistance of chemotherapy, radiotherapy of cancer. Biochim Biophys Acta Mol Cell Res. 2020. 1867(5): 118659.

37. Yamaguchi, $\mathrm{K}$, et al. Discovery of chemical probes that suppress Wnt/beta-catenin signaling through high-throughput screening. Cancer Sci. 2020. 111(3): 783-794.

38. Jin, B, et al. Detailed studies on the anticancer action of rosmarinic acid in human Hep-G2 liver carcinoma cells: evaluating its effects on cellular apoptosis, caspase activation and suppression of cell migration and invasion. J BUON. 2020. 25(3): 1383-1389.

39. $\mathrm{Li}, \mathrm{JQ}$, et al. Metabolomics profiling reveals the mechanism of caffeic acid in extending lifespan in Drosophila melanogaster. Food Funct. 2020. 11(9): 8202-8213.

40. Xie, Y, et al. Caffeic acid derivatives: a new type of influenza neuraminidase inhibitors. Bioorg Med Chem Lett. 2013. 23(12): 3556-3560.

\section{Figures}




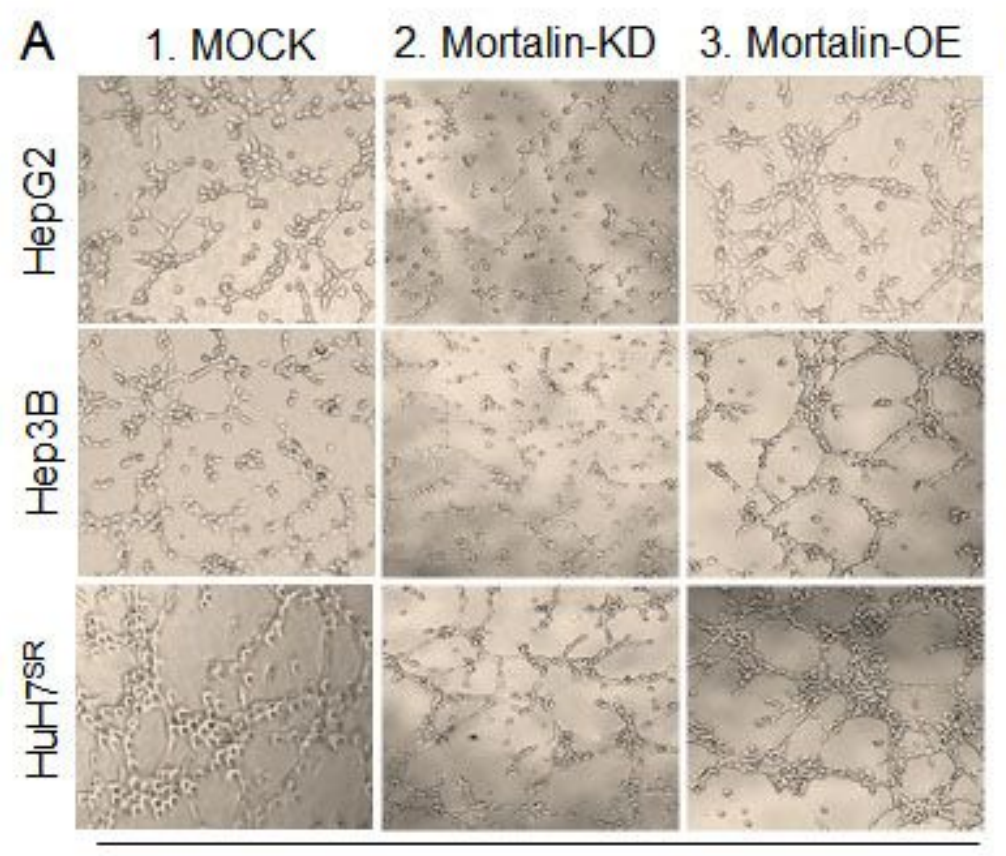

Conditioned Medium

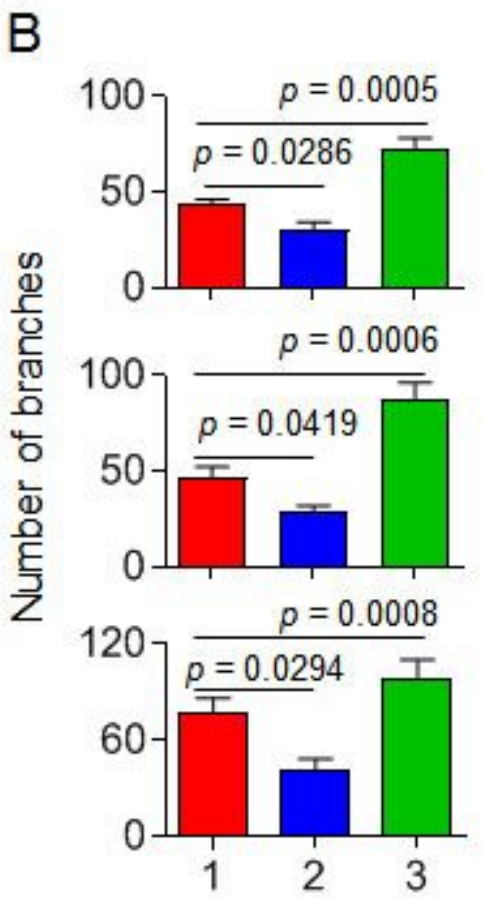

C 1. MOCK 2. Mortalin-KD

\section{Mortalin-OE}

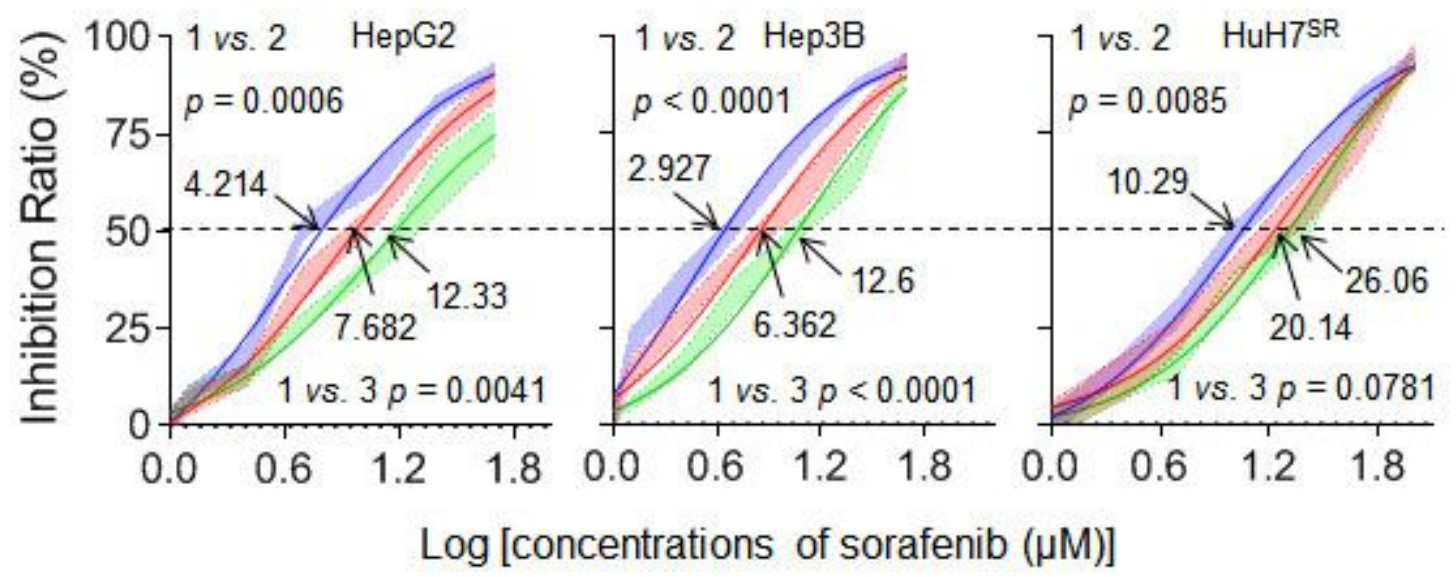

\section{Figure 1}

Mortalin caused angiogenesis and sorafenib resistance in HCC cells. HepG2, Hep3B and HuH7SR cells were transfected by mortalin-siRNA (knockdown, KD) or mortalin-Flag plasmid (overexpression, OE). (A) Capillary tube formation assay analyses of the effects of mortalin on the tube formation in HUVECs. (B) Quantitative analysis. (C) After the above-mentioned three HCC cells were transfected by mortalin-siRNA or mortalin-Flag plasmid, they were treated by different concentrations of sorafenib for $24 \mathrm{~h}$. The cell viability was determined in triplicate, and the IC50s were calculated. 


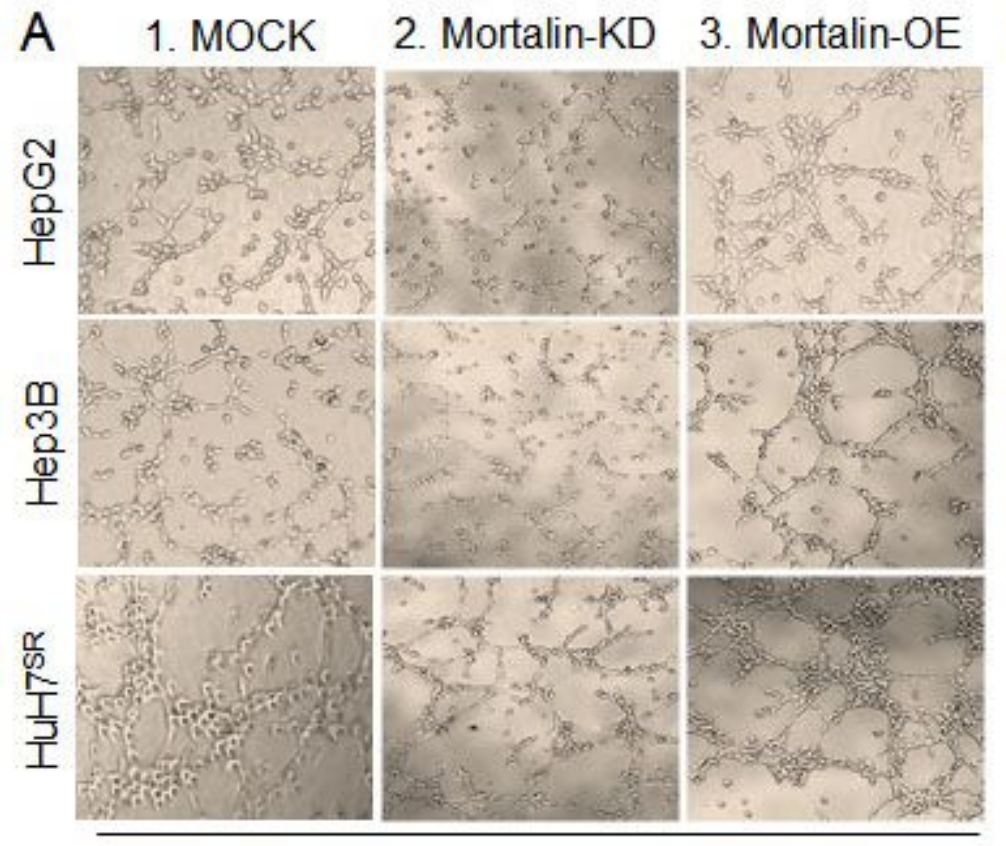

Conditioned Medium

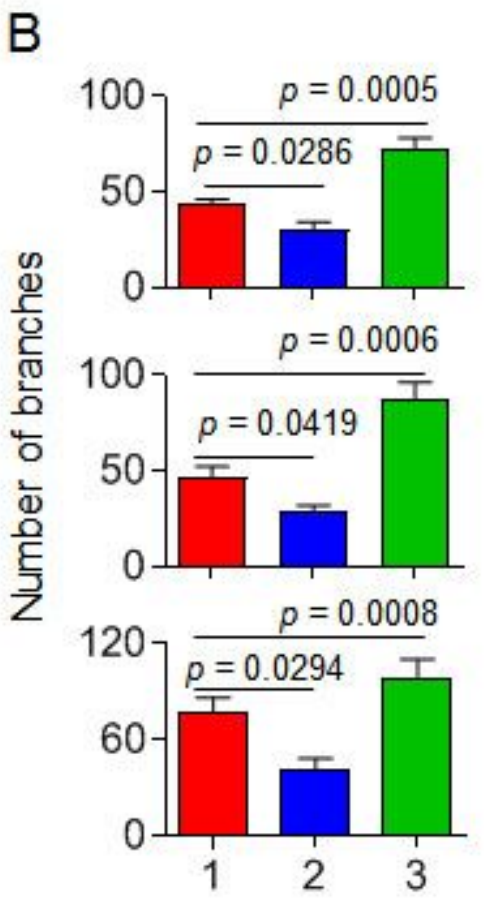

C 1. MOCK 2. Mortalin-KD

\section{Mortalin-OE}

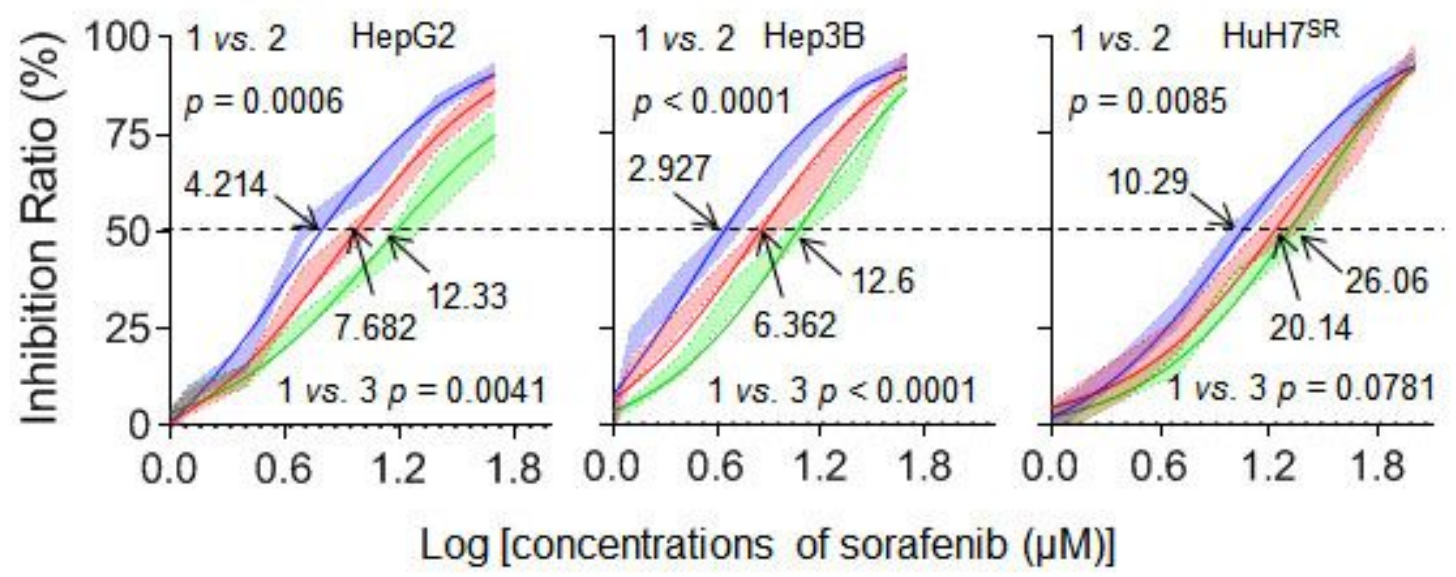

\section{Figure 1}

Mortalin caused angiogenesis and sorafenib resistance in HCC cells. HepG2, Hep3B and HuH7SR cells were transfected by mortalin-siRNA (knockdown, KD) or mortalin-Flag plasmid (overexpression, OE). (A) Capillary tube formation assay analyses of the effects of mortalin on the tube formation in HUVECs. (B) Quantitative analysis. (C) After the above-mentioned three HCC cells were transfected by mortalin-siRNA or mortalin-Flag plasmid, they were treated by different concentrations of sorafenib for $24 \mathrm{~h}$. The cell viability was determined in triplicate, and the IC50s were calculated. 


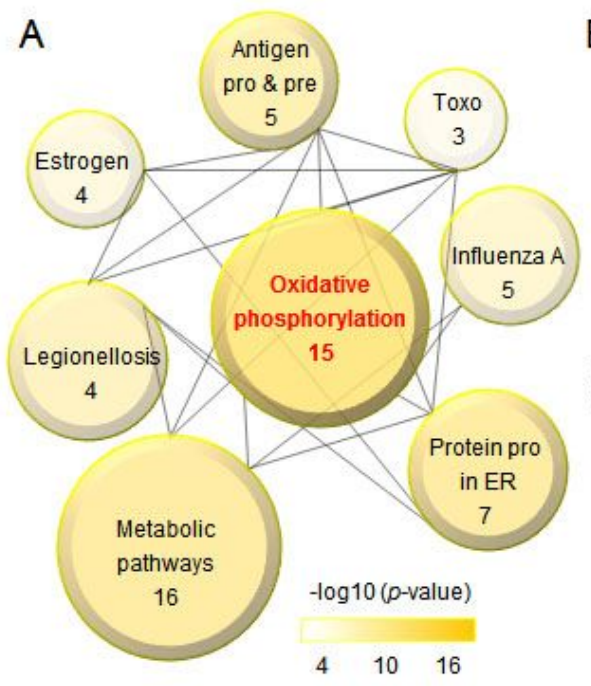

Pathway Network with Mortalin as the core
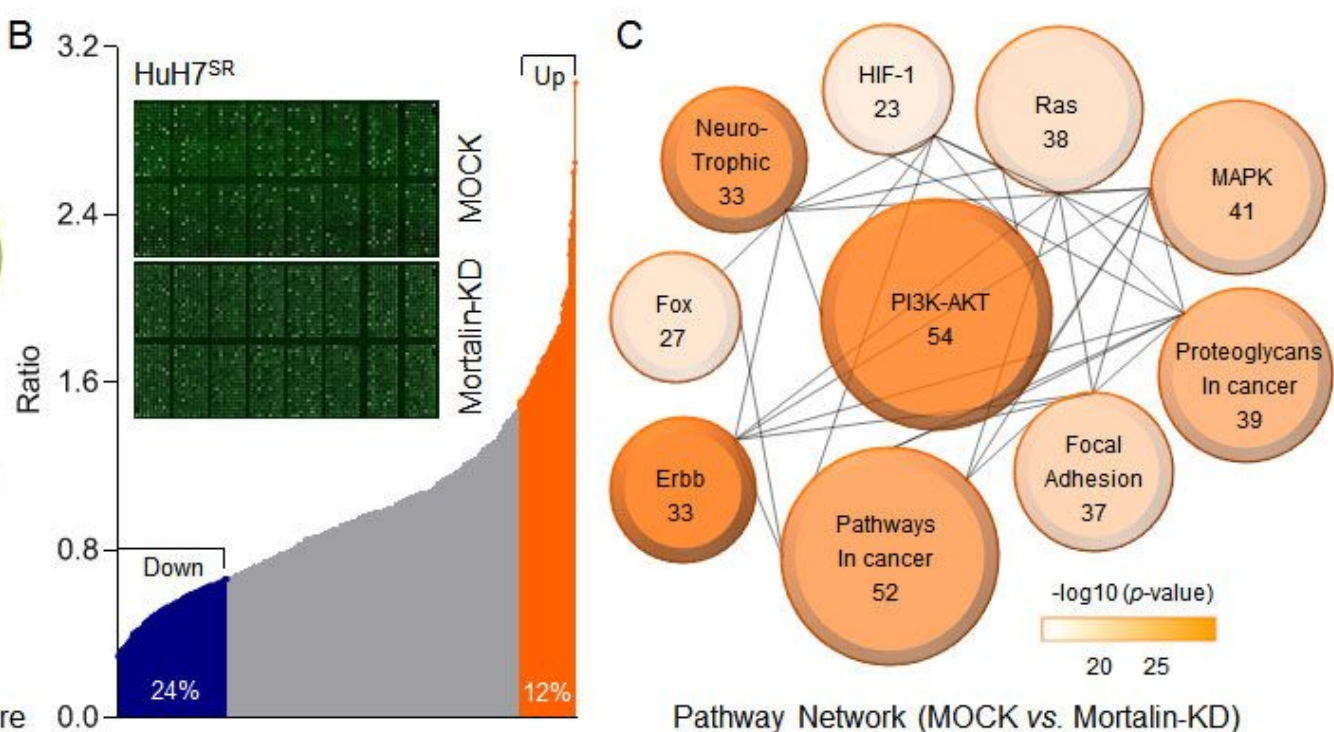

Pathway Network (MOCK vs. Mortalin-KD)

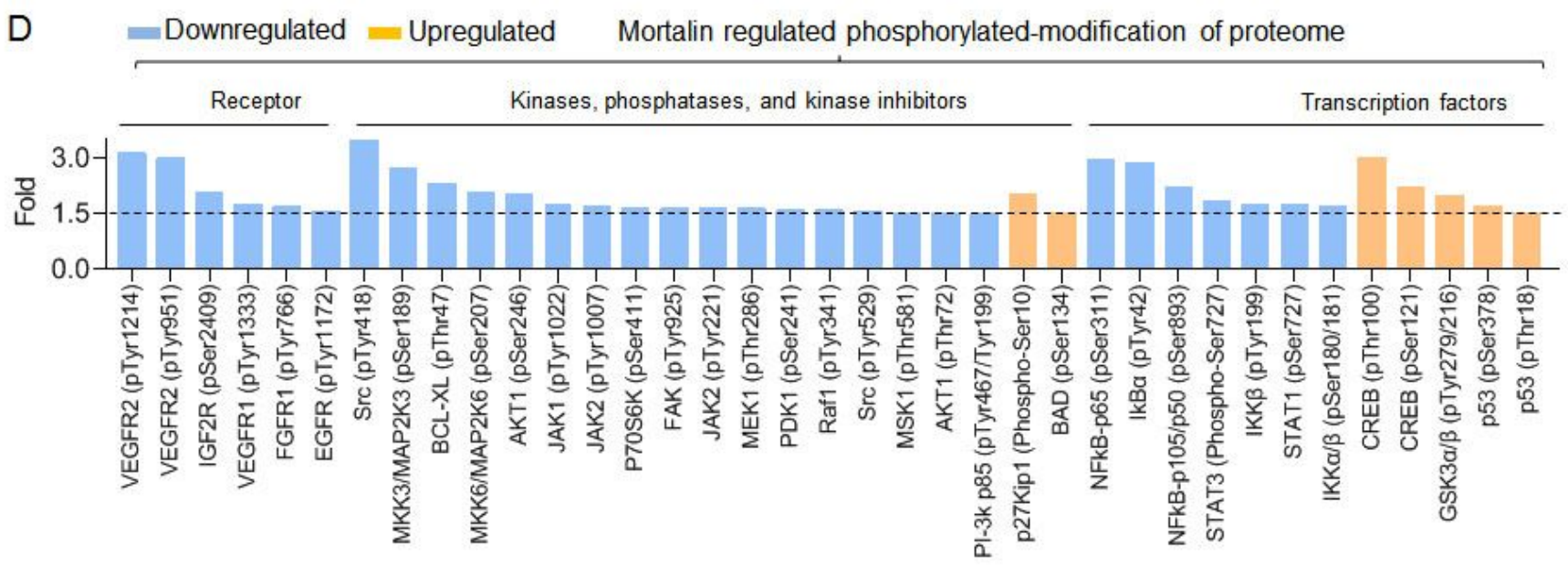

\section{Figure 2}

Mortalin regulated phosphorylated modification of cancer associated proteome in HCC cells. (A) KEGG pathway enrichment analyses of the 20 most frequently altered neighbor interactors and 30 indirect interactors around mortalin from STRING database, the size of the circle indicates the number of genes enriched in the item, and different color shade represents the size of $p$ value. (B) phospho-antibody microarray analysis of the expression changes of phospho-proteins upon mortalin knockdown in HuH7SR cells. Phosphorylation levels up-regulated more than $50 \%$ ( 1.5 fold) were shown in orange, and down-regulated more than 33\% (1.5 fold) were shown in blue. (C) KEGG pathway enrichment analyses of the proteins whose phosphorylation levels up-regulated/down-regulated more than 1.5-fold upon mortalin-knockdown, and the top 10 pathways were shown. (D) Phospho-antibody microarray data showing the phosphorylation levels of critical receptors, kinases, phosphatases, kinase inhibitors, and transcription factors which involved in top 5 pathways listed in panel (C). 


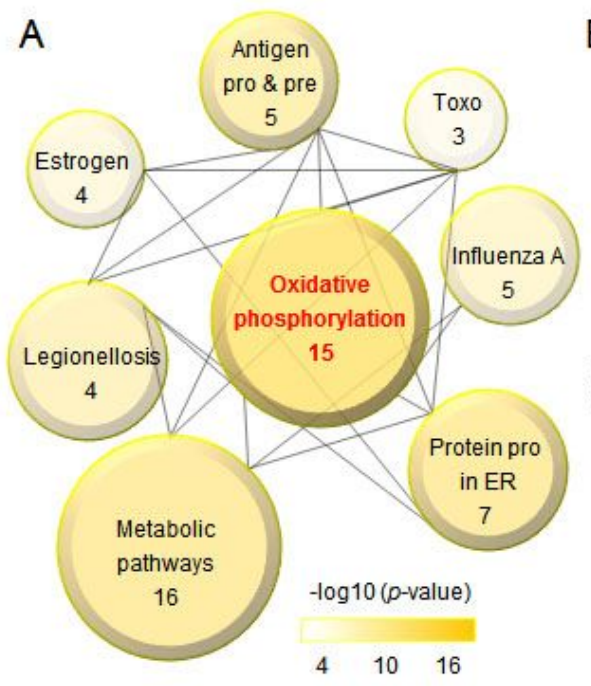

Pathway Network with Mortalin as the core
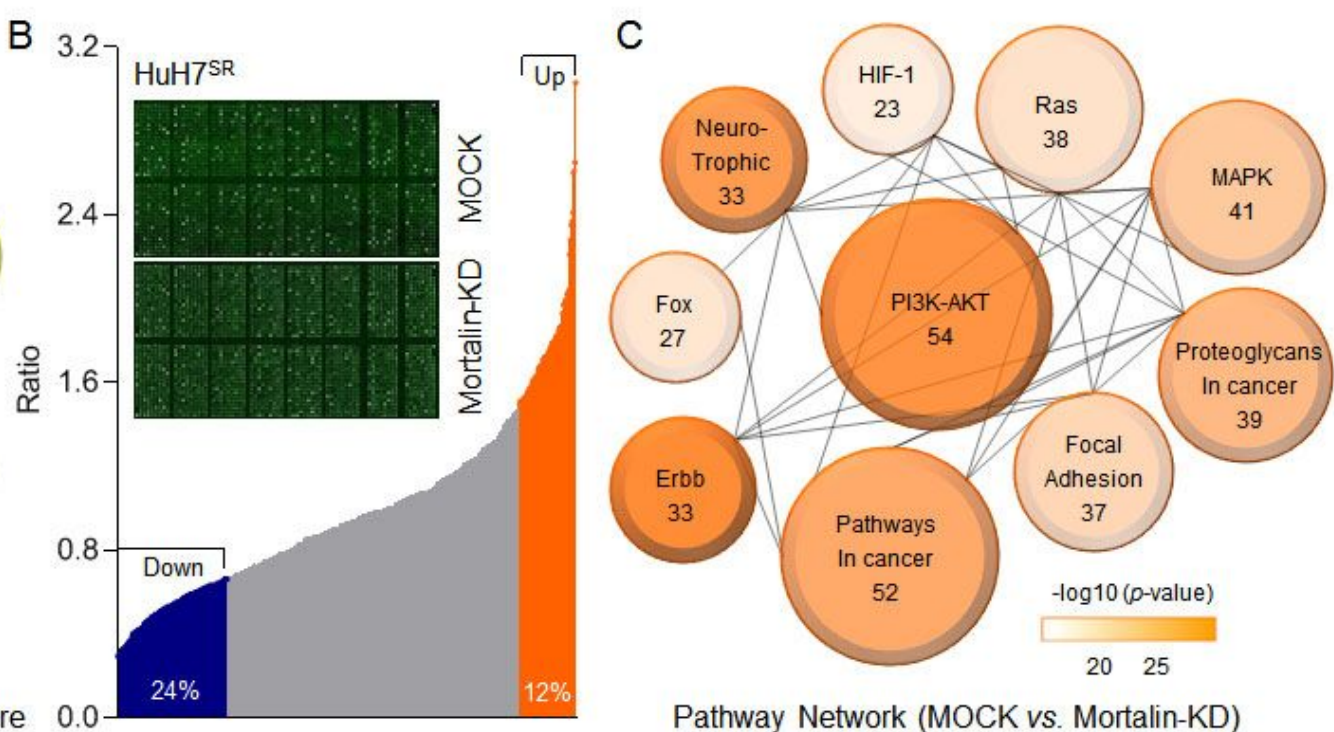

Pathway Network (MOCK vs. Mortalin-KD)

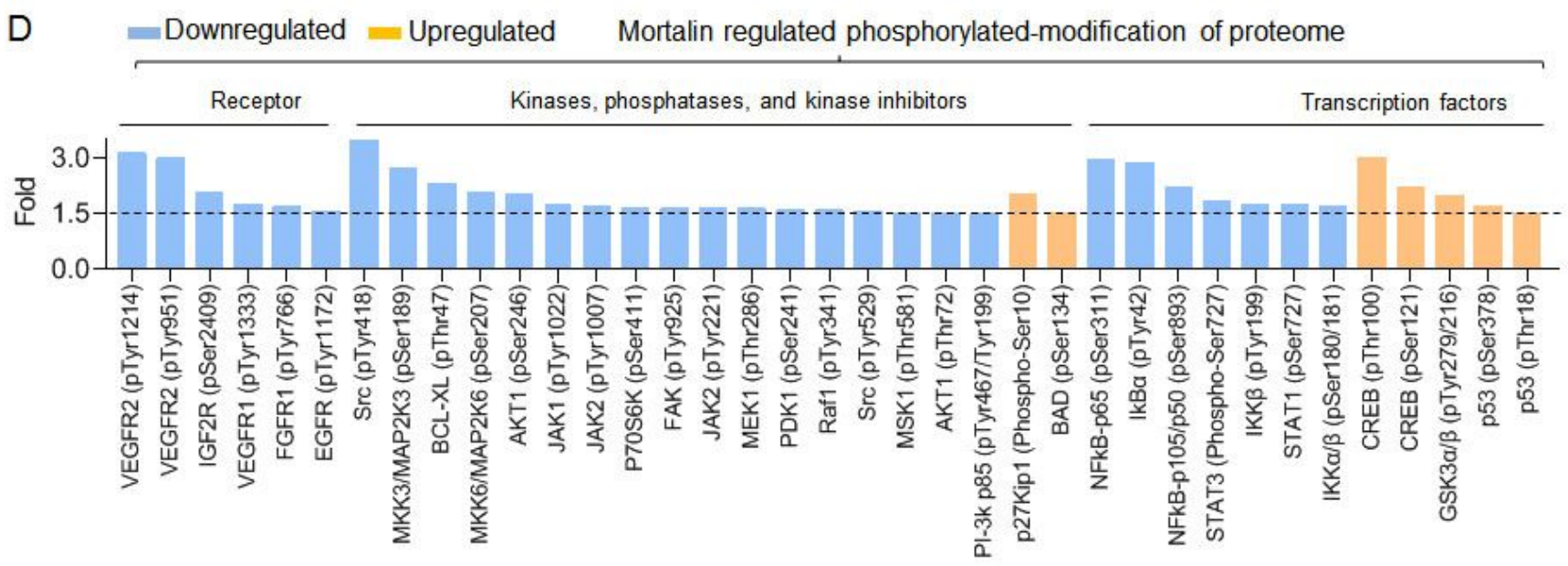

\section{Figure 2}

Mortalin regulated phosphorylated modification of cancer associated proteome in HCC cells. (A) KEGG pathway enrichment analyses of the 20 most frequently altered neighbor interactors and 30 indirect interactors around mortalin from STRING database, the size of the circle indicates the number of genes enriched in the item, and different color shade represents the size of $p$ value. (B) phospho-antibody microarray analysis of the expression changes of phospho-proteins upon mortalin knockdown in HuH7SR cells. Phosphorylation levels up-regulated more than $50 \%$ ( 1.5 fold) were shown in orange, and down-regulated more than 33\% (1.5 fold) were shown in blue. (C) KEGG pathway enrichment analyses of the proteins whose phosphorylation levels up-regulated/down-regulated more than 1.5-fold upon mortalin-knockdown, and the top 10 pathways were shown. (D) Phospho-antibody microarray data showing the phosphorylation levels of critical receptors, kinases, phosphatases, kinase inhibitors, and transcription factors which involved in top 5 pathways listed in panel (C). 


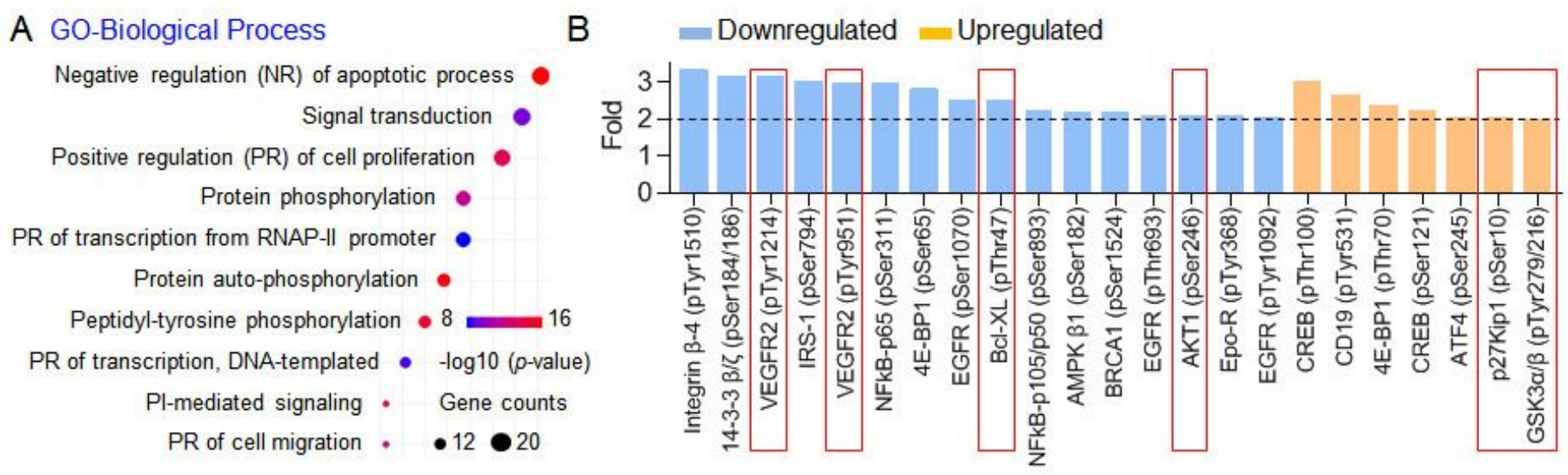

C Downregulated $=$ Upregulated
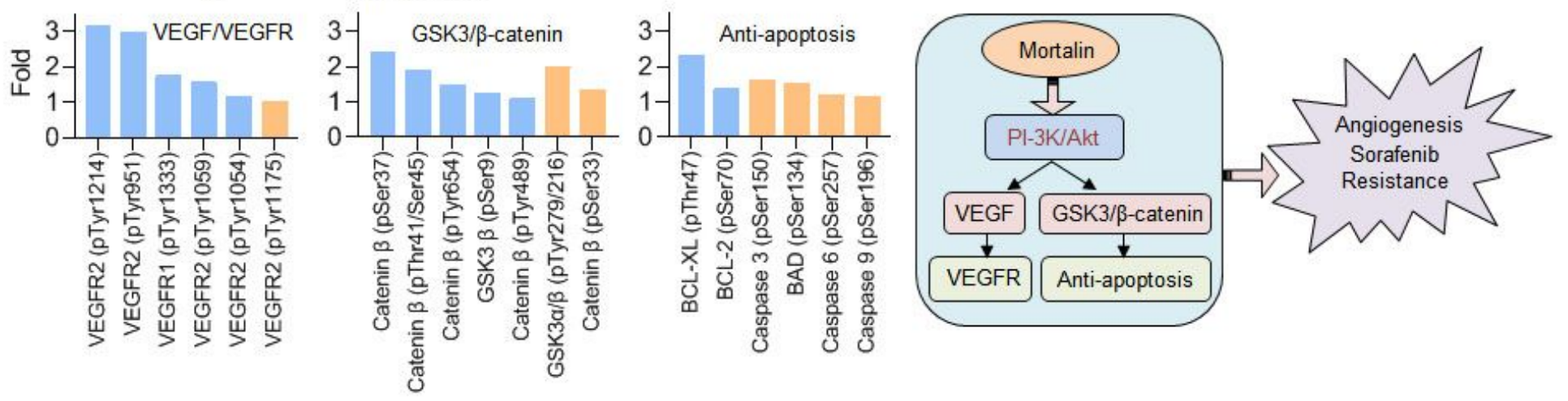

\section{Figure 3}

Identification of PI-3K/Akt as an important downstream factor, regulating VEGF and GSK3/ $\beta$-catenin in HCC cells. (A) GO biological process analysis of the 54 proteins enriched in PI-3K/Akt pathway. (B) The proteins of $\mathrm{PI}-3 \mathrm{~K} / \mathrm{Akt}$ signaling pathway with the most significant changes in phosphorylation levels (more than 2-fold). (C) The changes of phosphorylation levels of proteins involved in VEGF/VEGFR, GSK3/ $\beta$-catenin, and apoptosis process. (D) A sketch map speculating the potential mechanisms involved in the mortalin-induced angiogenesis and sorafenib resistance. 


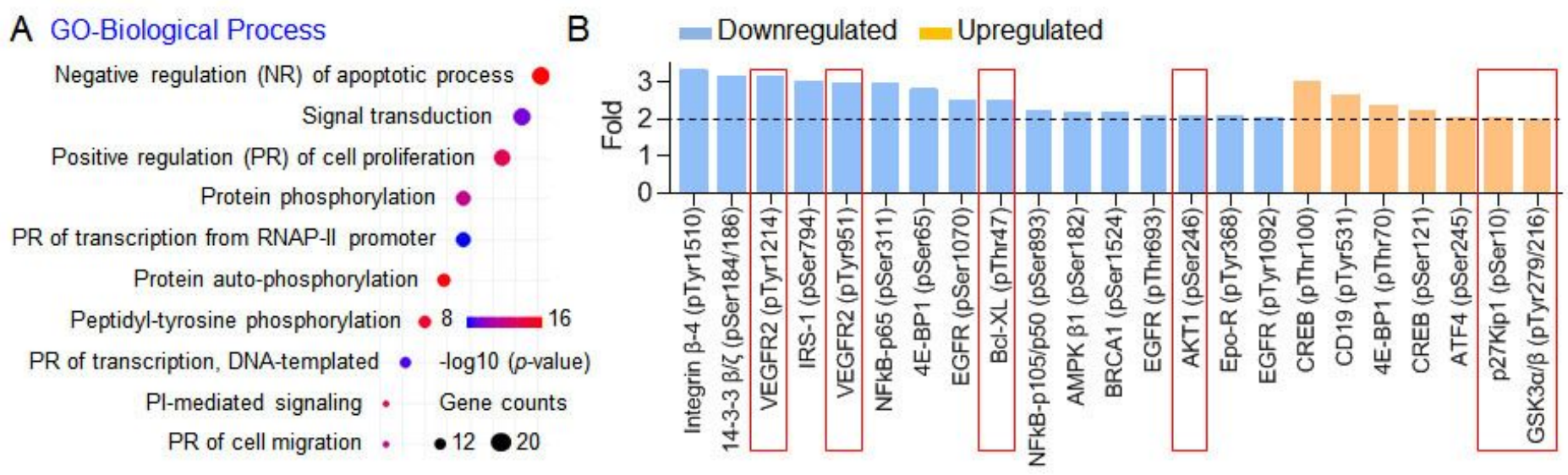

C Downregulated $=$ Upregulated
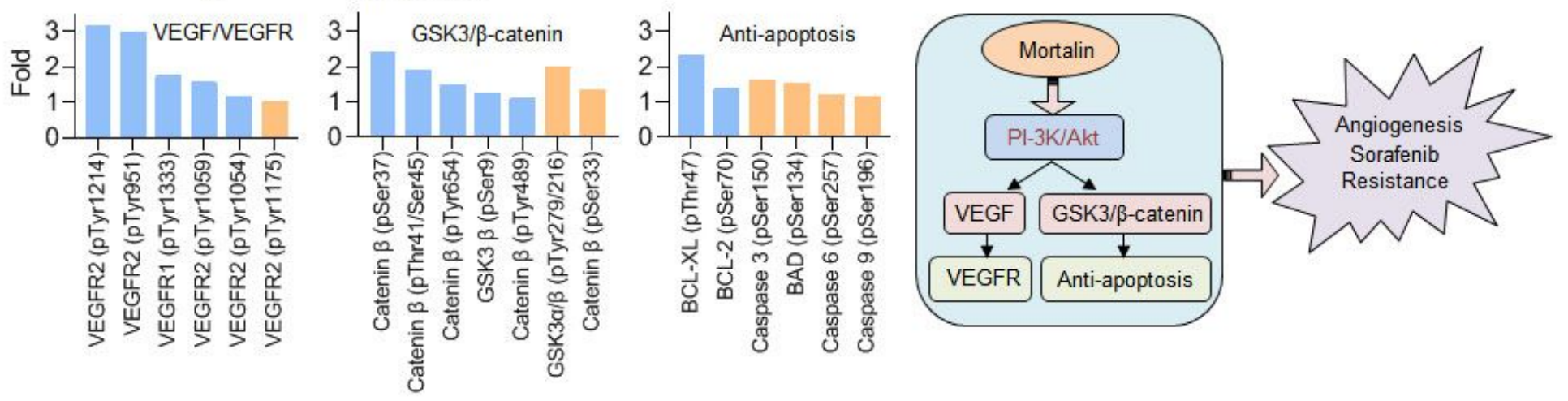

\section{Figure 3}

Identification of PI-3K/Akt as an important downstream factor, regulating VEGF and GSK3/ $\beta$-catenin in HCC cells. (A) GO biological process analysis of the 54 proteins enriched in PI-3K/Akt pathway. (B) The proteins of $\mathrm{PI}-3 \mathrm{~K} / \mathrm{Akt}$ signaling pathway with the most significant changes in phosphorylation levels (more than 2-fold). (C) The changes of phosphorylation levels of proteins involved in VEGF/VEGFR, GSK3/ $\beta$-catenin, and apoptosis process. (D) A sketch map speculating the potential mechanisms involved in the mortalin-induced angiogenesis and sorafenib resistance. 


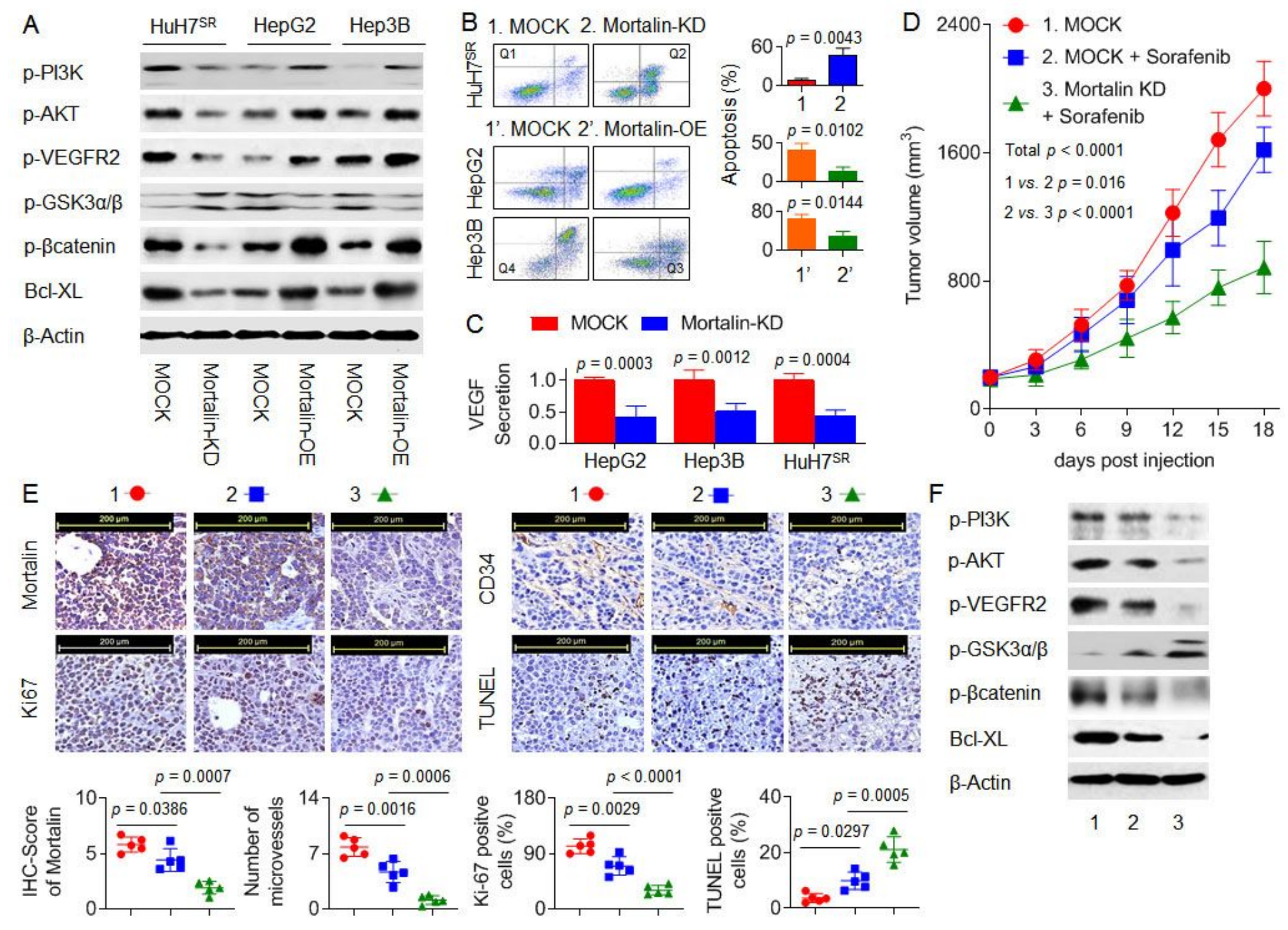

\section{Figure 4}

Verification of microarray and bioinformatics results in vitro and in vivo. (A and B) HuH7SR cells were transfected by mortalin-siRNA, while HepG2 and Hep3B cells were transfected by mortalin-Flag plasmid. (A) Western blot analyses of the expressions of PI3K-p85 (Tyr458), Akt (Ser473), VEGFR2 (Tyr951), GSK3 $\beta$ (Tyr216), $\beta$-catenin (Thr41/Ser 45), and Bcl-XL. (B) After transfection, these cells were treated by $10 \mu \mathrm{M}$ of sorafenib. Flow cytometry analyses of the percentage of cell apoptosis (Q1: necrotic cells, Q2: late apoptosis, Q3: early apoptosis, Q4: living cells). The right graph was a statistical analysis of total apoptosis (Q2 + Q3). (C) HepG2, Hep3B, and HuH7SR cells were transfected by mortalin-siRNA, and then the conditioned mediums were collected. ELISA analyses in triplicate of VEGF protein secretion. (D to F) The HuH7SR cells xenograft tumors were treated by sorafenib alone or sorafenib plus mortalin-siRNA. (D) The volumes of xenografts tumors. (E) IHC staining of the mortalin, Ki67, CD34, as well as TUNEL sraining. (F) Western blot analyses of the expressions of proteins listed in panel (A). 


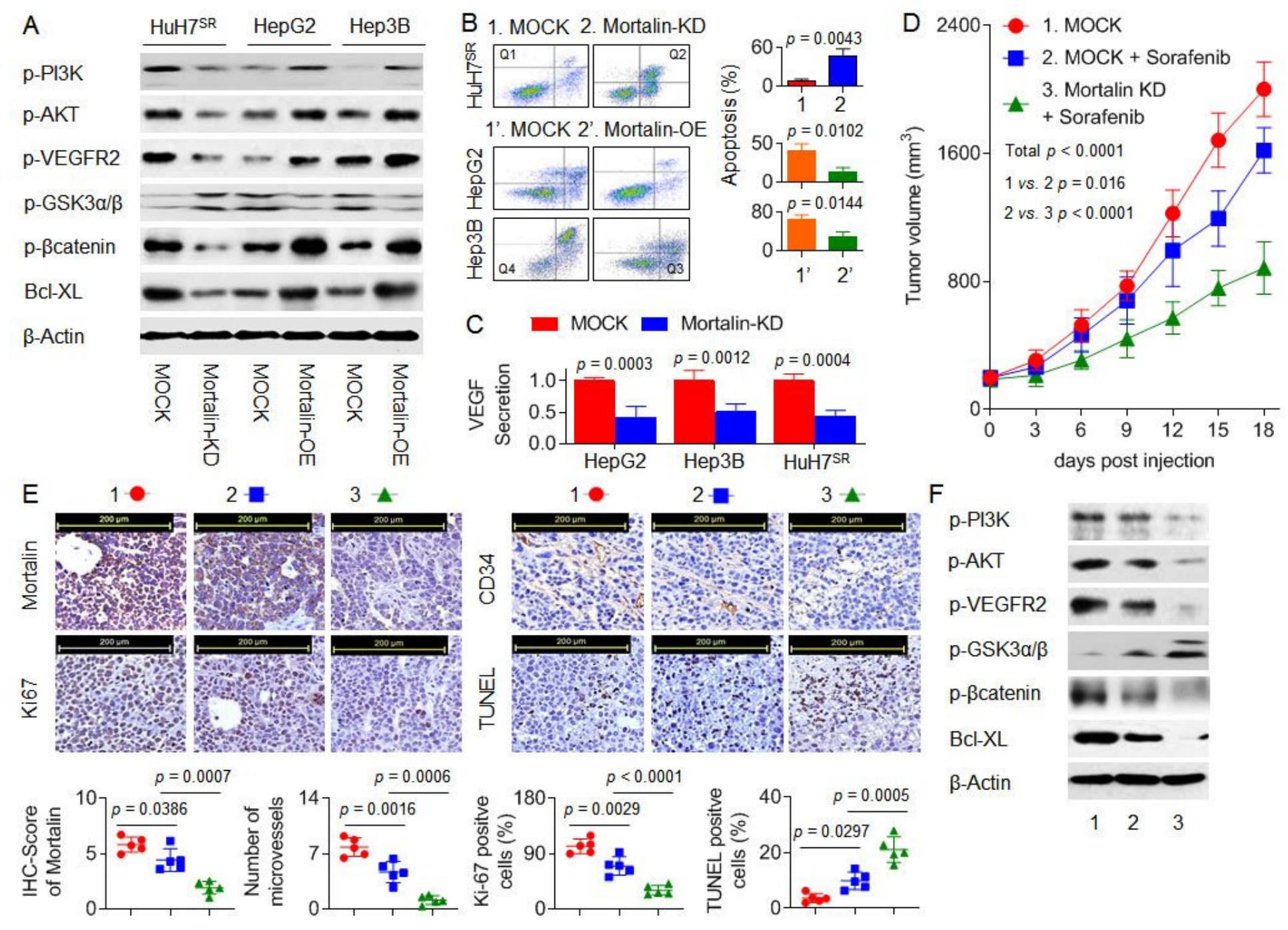

\section{Figure 4}

Verification of microarray and bioinformatics results in vitro and in vivo. (A and B) HuH7SR cells were transfected by mortalin-siRNA, while HepG2 and Hep3B cells were transfected by mortalin-Flag plasmid. (A) Western blot analyses of the expressions of PI3K-p85 (Tyr458), Akt (Ser473), VEGFR2 (Tyr951), GSK3 $\beta$ (Tyr216), $\beta$-catenin (Thr41/Ser 45), and Bcl-XL. (B) After transfection, these cells were treated by $10 \mu \mathrm{M}$ of sorafenib. Flow cytometry analyses of the percentage of cell apoptosis (Q1: necrotic cells, Q2: late apoptosis, Q3: early apoptosis, Q4: living cells). The right graph was a statistical analysis of total apoptosis (Q2 + Q3). (C) HepG2, Hep3B, and HuH7SR cells were transfected by mortalin-siRNA, and then the conditioned mediums were collected. ELISA analyses in triplicate of VEGF protein secretion. (D to F) The HuH7SR cells xenograft tumors were treated by sorafenib alone or sorafenib plus mortalin-siRNA. (D) The volumes of xenografts tumors. (E) IHC staining of the mortalin, Ki67, CD34, as well as TUNEL sraining. (F) Western blot analyses of the expressions of proteins listed in panel (A). 

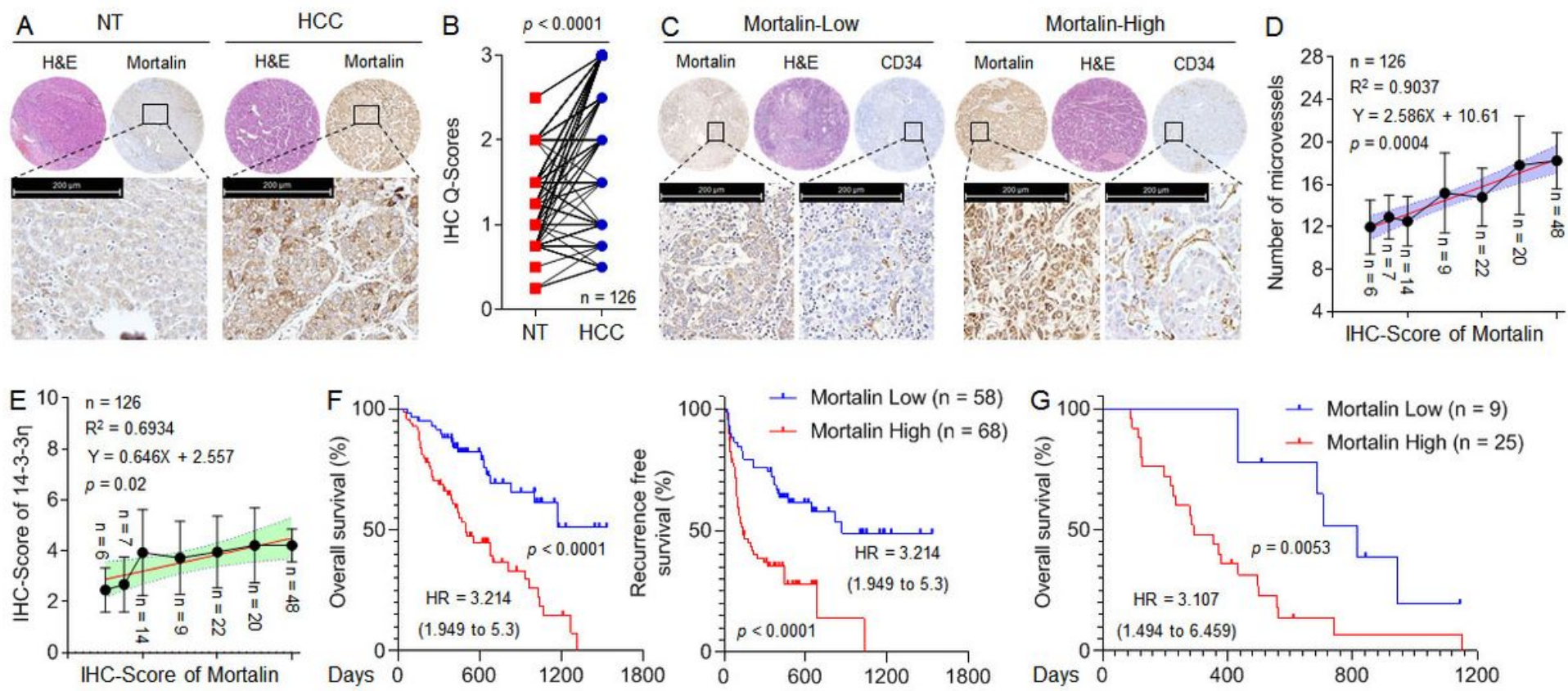

\section{Figure 5}

The clinical significance of mortalin in HCC. (A and B) Tissue microarray and IHC analyses of the mortalin in HCC samples compared with their adjacent non-tumor liver tissues. (C) Tissue microarray and IHC analyses of mortalin and CD34 in HCC samples. (D) Relationship between mortalin expression and the number of microvessels. (E) Tissue microarray and IHC analyses of mortalin and 14-3-3n in HCC samples, and their relationship was exhibited. (F) Kaplan-Meier analyses of the prognostic significances of mortalin in 126 HCC patients. (G) Kaplan-Meier analyses of the prognostic significances of mortalin in 34 advanced recurrent HCC patients.
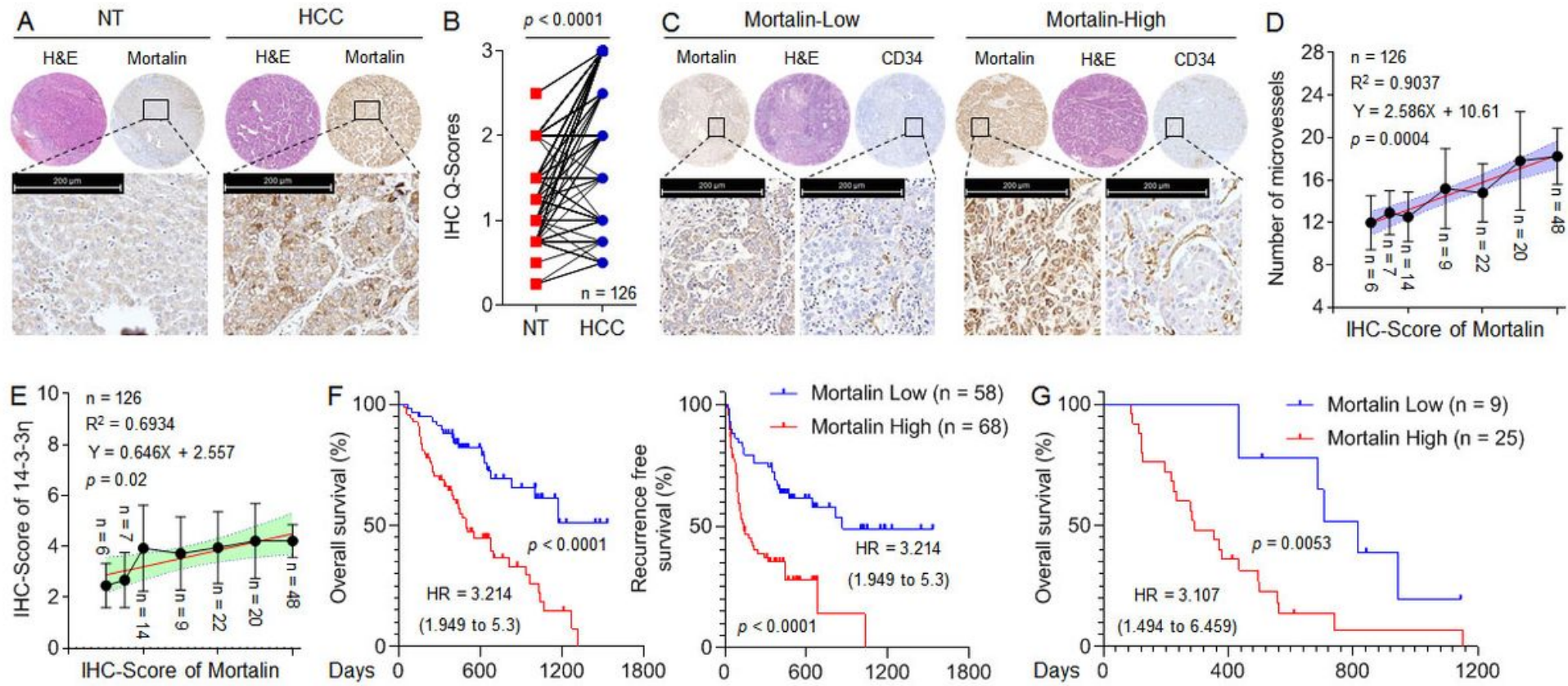

Figure 5 
The clinical significance of mortalin in HCC. (A and B) Tissue microarray and IHC analyses of the mortalin in HCC samples compared with their adjacent non-tumor liver tissues. (C) Tissue microarray and IHC analyses of mortalin and CD34 in HCC samples. (D) Relationship between mortalin expression and the number of microvessels. (E) Tissue microarray and IHC analyses of mortalin and 14-3-3n in HCC samples, and their relationship was exhibited. (F) Kaplan-Meier analyses of the prognostic significances of mortalin in 126 HCC patients. (G) Kaplan-Meier analyses of the prognostic significances of mortalin in 34 advanced recurrent HCC patients.
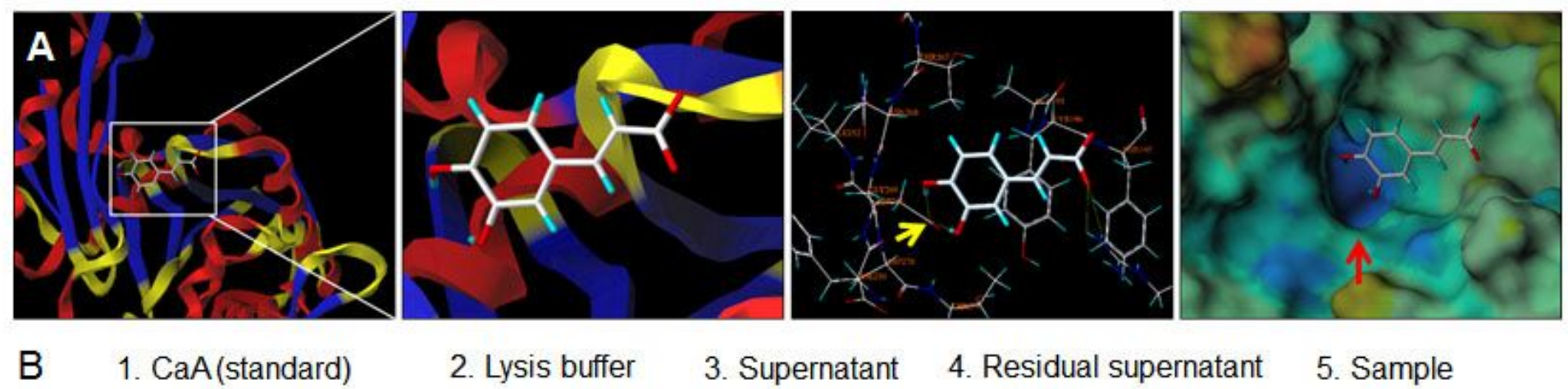

2. Lysis buffer

3. Supernatant

4. Residual supernatant

5. Sample
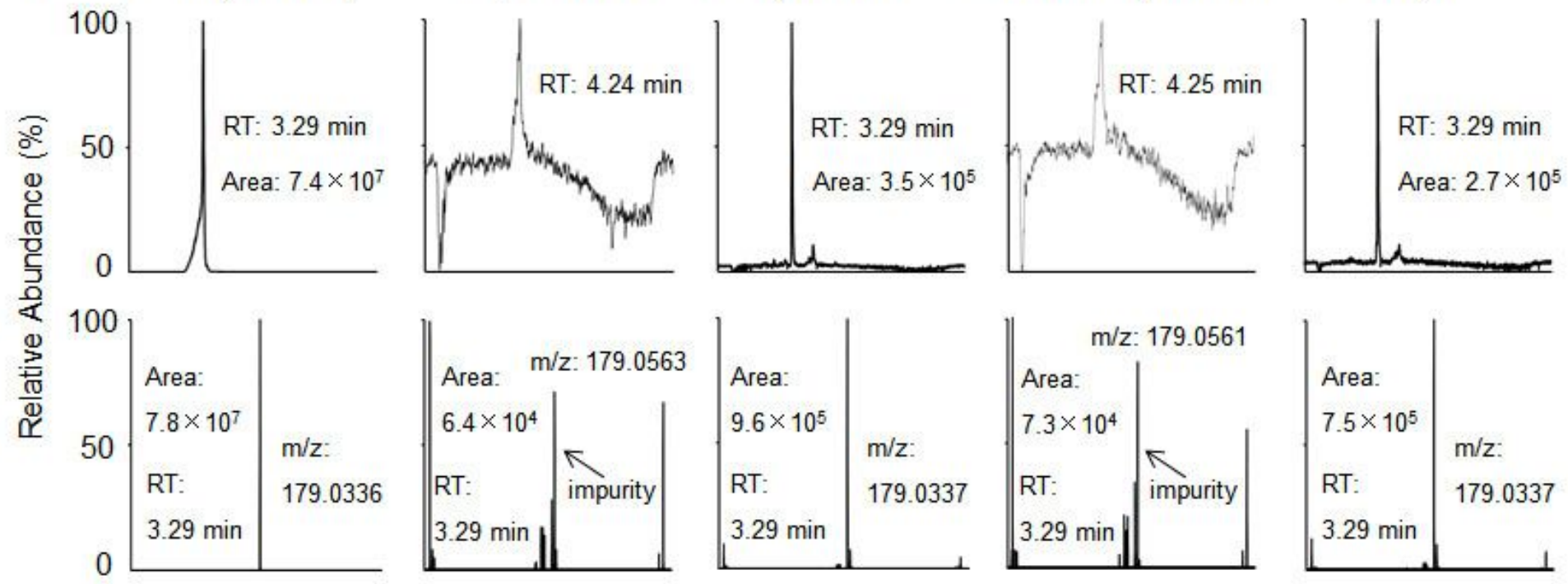

C MG-132
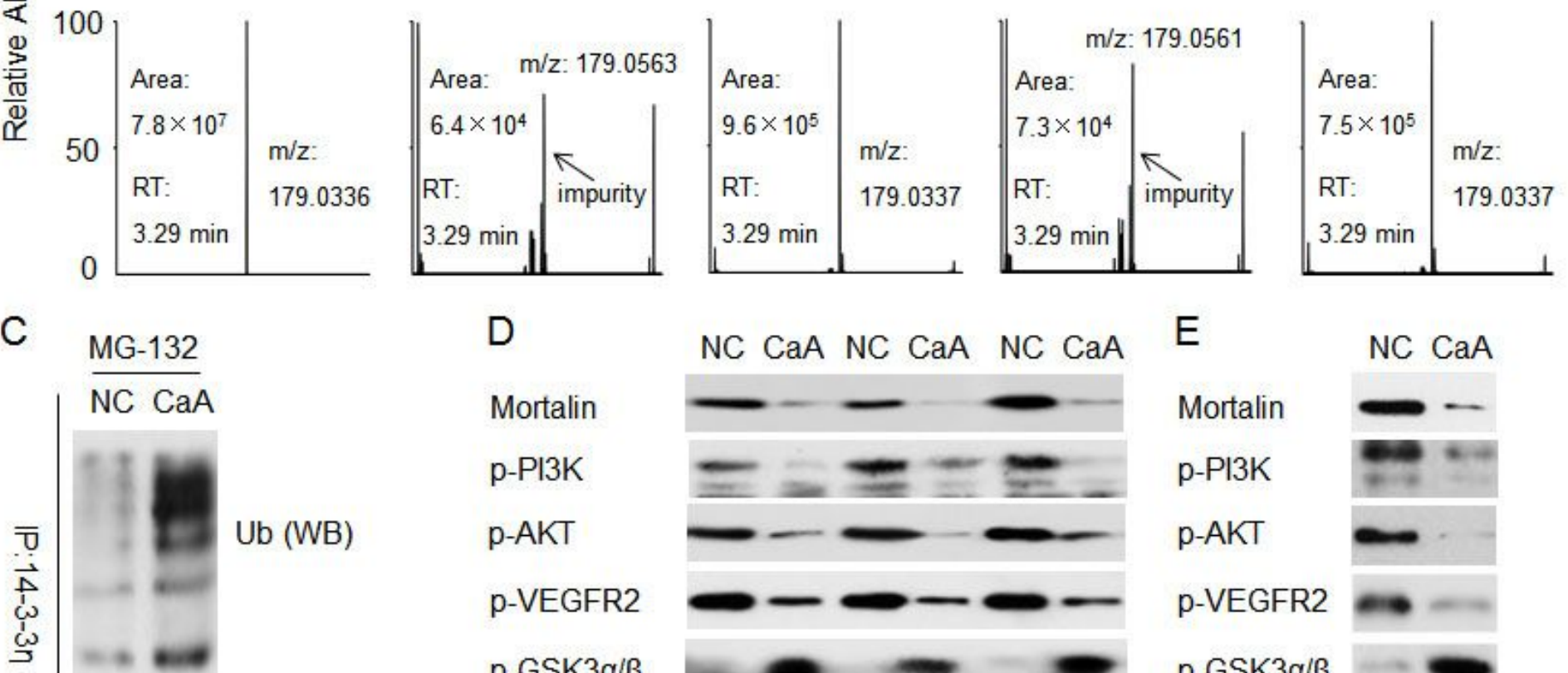

D

Mortalin

p-PI3K

p-AKT

p-VEGFR2

p-GSK3 $\alpha / \beta$

NC CaA NC CaA NC CaA

E

Mortalin (WB) p-ßcatenin

Mortalin

$\mathrm{BCl}-\mathrm{XL}$

$\beta$-Actin

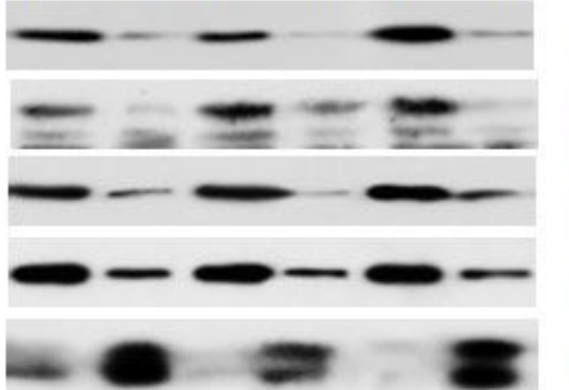

Mortalin

p-PI3K

p-AKT

p-VEGFR2

p-GSK3 $\alpha / \beta$

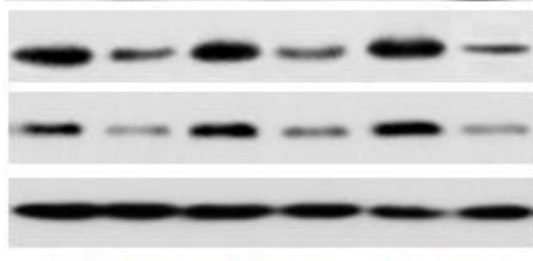

p-ßcatenin

$\mathrm{BCl}-\mathrm{XL}$

$\beta$-Actin

$\mathrm{NC} \mathrm{CaA}$

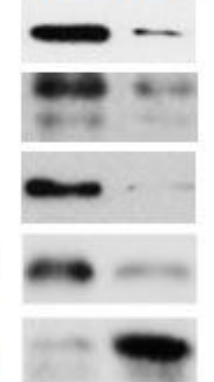

HepG2 Hep3B HuH7sR 


\section{Figure 6}

Identified a novel potential chemical inhibitor for mortalin: CaA. (A) SYBYL-X soft-ware analyses of the binding of $\mathrm{CaA}$ to mortalin. After HuH7SR cells were pre-treated by $20 \mu \mathrm{M}$ of MG-132 for $2 \mathrm{~h}$, they were exposed to $20 \mu \mathrm{M}$ of $\mathrm{CaA}$ for $6 \mathrm{~h}$. The mortalin was immunoprecipitated with the specific antibody. (B) $\mathrm{LC} / \mathrm{MS}$ analyses of the content of CaA in mortalin-immunoprecipitation complex. (C) Western blot analyses of the expression of ubiquitin in mortalin-immunoprecipitation complex. (D) HepG2, Hep3B, and HuH7SR cells were treated by $20 \mu \mathrm{M}$ of $\mathrm{CaA}$ for $24 \mathrm{~h}$. Western blot analyses of the expressions of mortalin, PI3K-p85 (Tyr458), Akt (Ser473), VEGFR2 (Tyr951), GSK3ß (Tyr216), $\beta$-catenin (Thr41/Ser 45), and $\mathrm{Bcl}-\mathrm{XL}$. (E) Western blot analyses of the expressions of above-mentioned proteins in a previously established MHCC97H cells xenografts model, which was treated by CaA. 

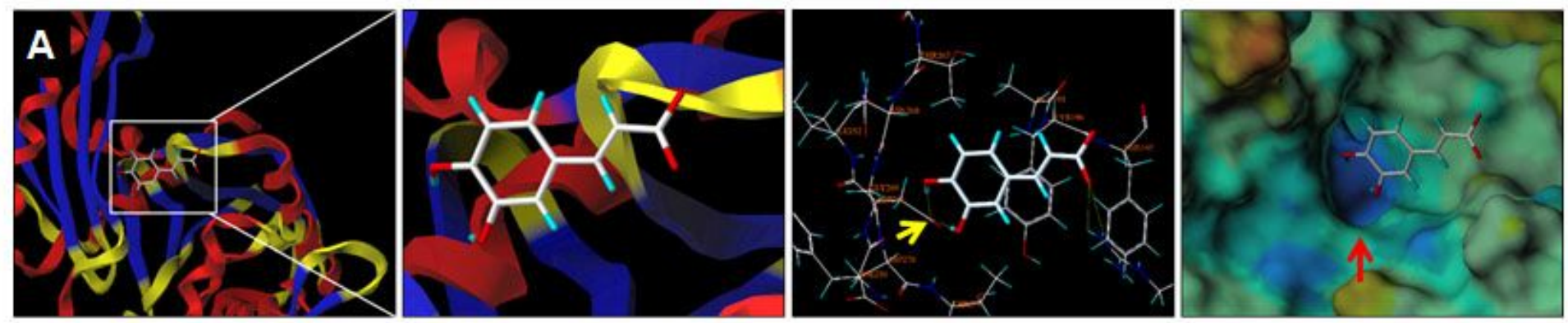

B 1. $\mathrm{CaA}$ (standard)

2. Lysis buffer

3. Supernatant

4. Residual supernatant

5. Sample
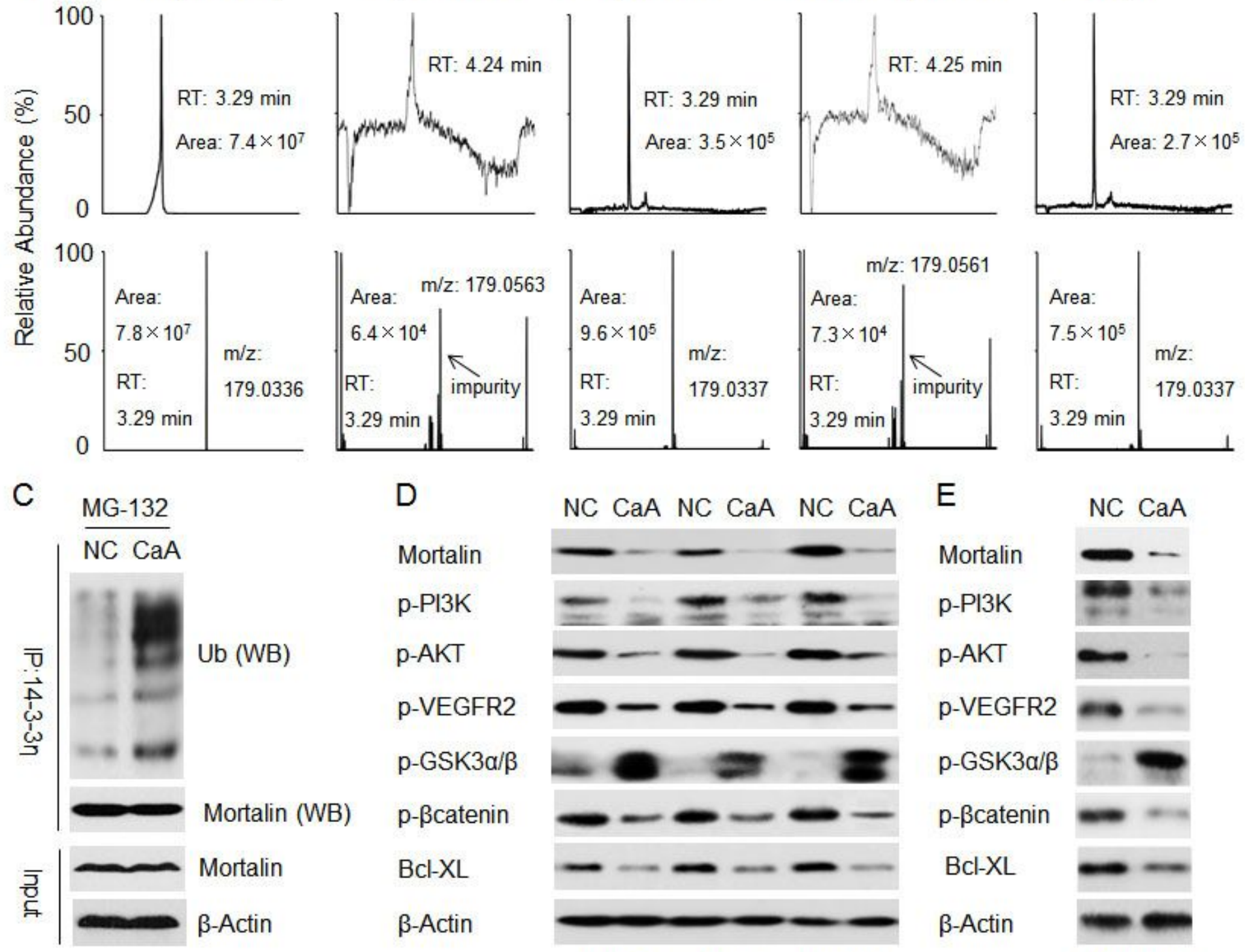

NC CaA NC CaA NC CaA

E

NC $\mathrm{CaA}$

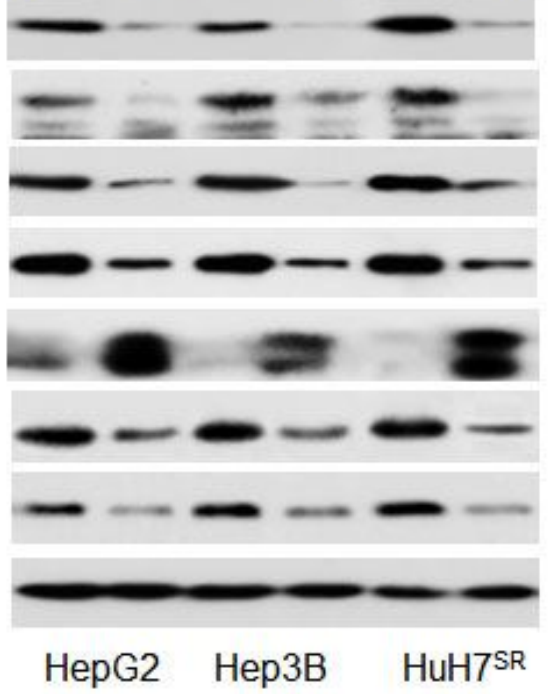

Mortalin

p-PI3K

p-AKT

p-VEGFR2

p-GSK3 $\alpha / \beta$

p-ßcatenin

$\mathrm{BCl}-\mathrm{XL}$

$\beta$-Actin

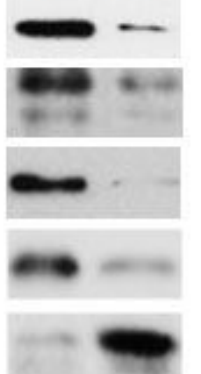

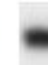

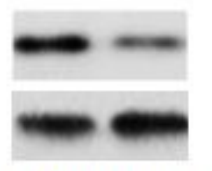

Xenografts

\section{Figure 6}

Identified a novel potential chemical inhibitor for mortalin: CaA. (A) SYBYL-X soft-ware analyses of the binding of $\mathrm{CaA}$ to mortalin. After HuH7SR cells were pre-treated by $20 \mu \mathrm{M}$ of MG-132 for $2 \mathrm{~h}$, they were exposed to $20 \mu \mathrm{M}$ of CaA for $6 \mathrm{~h}$. The mortalin was immunoprecipitated with the specific antibody. (B) $\mathrm{LC} / \mathrm{MS}$ analyses of the content of CaA in mortalin-immunoprecipitation complex. (C) Western blot analyses of the expression of ubiquitin in mortalin-immunoprecipitation complex. (D) HepG2, Hep3B, and 
HuH7SR cells were treated by $20 \mu \mathrm{M}$ of $\mathrm{CaA}$ for $24 \mathrm{~h}$. Western blot analyses of the expressions of mortalin, PI3K-p85 (Tyr458), Akt (Ser473), VEGFR2 (Tyr951), GSK3 $\beta$ (Tyr216), $\beta$-catenin (Thr41/Ser 45), and $\mathrm{Bcl}-\mathrm{XL}$. (E) Western blot analyses of the expressions of above-mentioned proteins in a previously established MHCC97H cells xenografts model, which was treated by CaA.

\section{Innovation point 1}

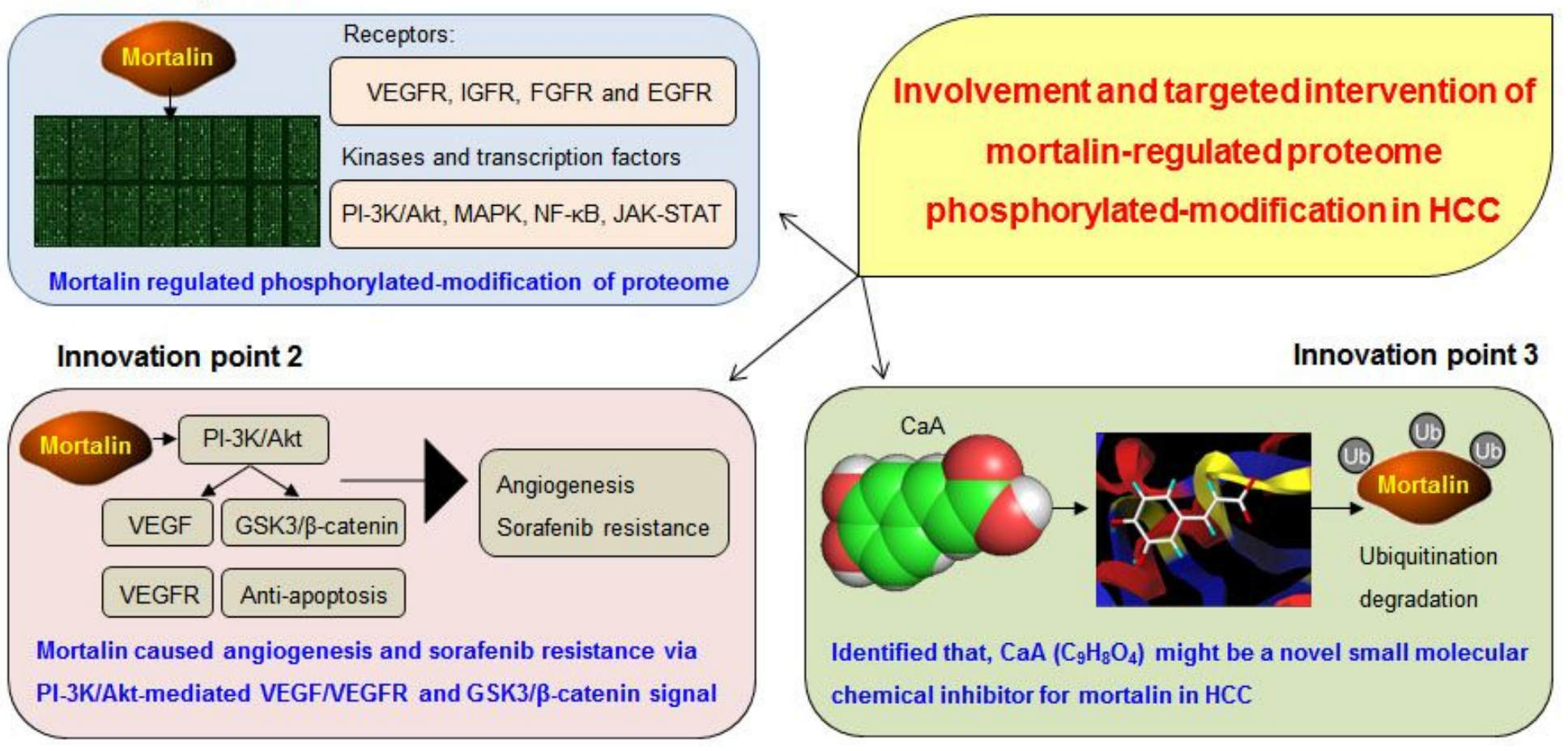

\section{Figure 7}

A sketch map summarizing the conclusions, innovations, and potential clinical significance of our present study 


\section{Innovation point 1}

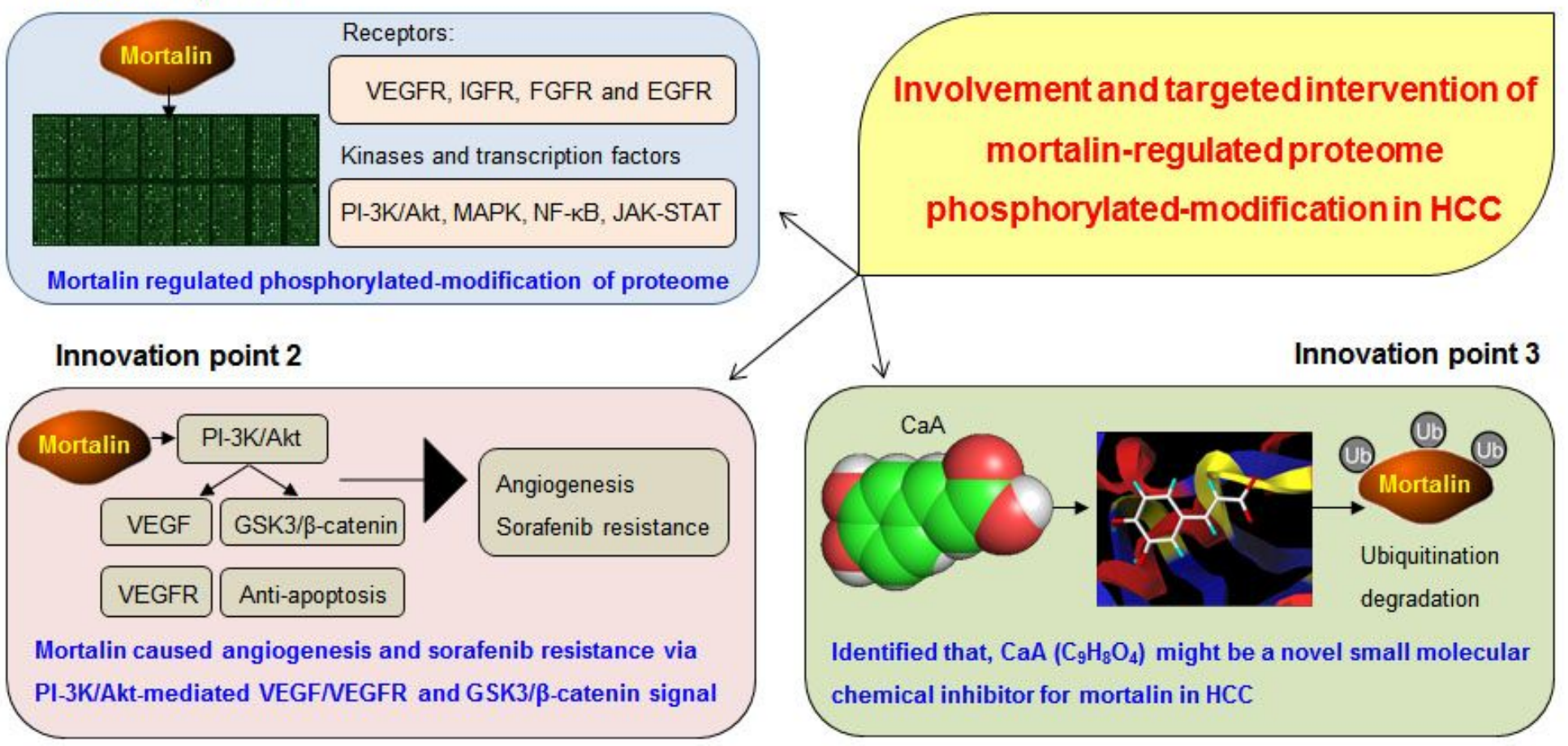

\section{Figure 7}

A sketch map summarizing the conclusions, innovations, and potential clinical significance of our present study

\section{Supplementary Files}

This is a list of supplementary files associated with this preprint. Click to download.

- Highlights.docx

- Highlights.docx

- AdditionalFiles.pdf

- AdditionalFiles.pdf 